\title{
"Se imprima y circule": administración y control del libro en el Reino de Navarra (1801-1831)
}

\author{
Javier RUIZ ASTIZ \\ Universidad Pública de Navarra. Nafarroako Unibertsitate Publikoa \\ jruizastiz@gmail.com
}

Recibido: Septiembre 2015

Aceptado: Noviembre 2015

Resumen: Este artículo pretende desentrañar el papel que desempeñó el Consejo Real de Navarra entre 1801 y 1831 a partir del análisis de los 87 expedientes de autorización de impresión que se conservan en el Archivo General de Navarra. Gracias a ellos seremos capaces de discernir el funcionamiento administrativo del proceso de edición en el reino a principios del siglo XIX, así como el objeto de dichas peticiones (licencias, censuras o reimpresiones), quiénes estaban detrás de las mismas y para qué tipo de obras se cursaban.

Palabras clave: Censura; Consejo Real; Licencia; Reino de Navarra; Siglo XIX.

"Se imprima y circule": management and control of the book into the Kingdom of Navarre (1801-1831)

\begin{abstract}
This article aims to unravel the role of Royal Council of Navarre between 1801 and 1831 from the analysis of the 87 printing authorization dossiers preserved into the General Archive of Navarre. Thanks to them we are able to discern the administrative operation of the editing process in the kingdom in early nineteenth century, and the purpose of such requests (licenses, censures or reprints), who was behind them and what type books were enrolled.
\end{abstract}

Keywords: Censorship; Kingdom of Navarre; License; Real Council; XIX century.

\section{INTRODUCCIÓN}

A principios del siglo XIX la expansión de los ideales revolucionarios por todo el continente europeo se fue plasmando en distintas medidas legales que tendían a romper con el conocido como Antiguo Régimen. En el caso español uno de los principales hitos de aquella época sería la Constitución de Cádiz, punto de partida del liberalismo decimonónico que protagonizará enconadas disputas con los sectores más moderados durante toda la centuria. En dicho contexto político, militar y legal el uso de la imprenta comenzó a cambiar. Las convulsas primeras décadas de aquel siglo constituyeron el fin de unos modos heredados desde 1558 momento en que entró en vigor el modelo administrativo diseñado por Felipe II- 
para ir poco a poco adaptándose a las nuevas exigencias que pregonaba la recién nacida sociedad liberal.

En medio de todo aquello encontramos al todavía Reino de Navarra. Un territorio que hasta 1841 siguió manteniendo buena parte de sus prerrogativas administrativas y legales privativas como un espacio diferente al resto, y más cuando desde los decretos de Nueva Planta el único consejo territorial que seguía operando en materia de imprenta, al margen del castellano, era el de Navarra. En consecuencia, a lo largo de este estudio trataremos de analizar el papel y las funciones que, aún en las primeras décadas del siglo XIX, siguió ostentando el Consejo Real de Navarra en todo lo relacionado con la industria editorial.

Bien es cierto que en particular vamos a centrarnos en uno de sus cometidos más relevantes, caso de la concesión de licencias para la impresión de textos. Para esto ha resultado clave el hecho de contar con 87 expedientes que se conservan en el Archivo General de Navarra en la sección de Tribunales Reales, bajo la denominación "Impresión de libros. Expedientes de autorización" entre 1801 y 1831. Sin duda, se trata de un tipo de fuente documental de una extraordinaria validez para desentrañar no sólo el funcionamiento del Consejo Real de Navarra, sino al mismo tiempo los avatares del mercado editorial en un momento determinado. De este modo, el uso de dichos expedientes arroja notables ventajas para la Historia del Libro, pues nos permite:

- Conocer de primera mano la actividad administrativa del Consejo Real en materia de imprenta.

- Reconstruir el procedimiento de concesión de licencias de impresión.

- Comprobar el papel que desempeñaba la censura ante la edición de ciertos textos.

- Apreciar quiénes actuaron como editores promoviendo la publicación de libros en el reino.

- Evidenciar tanto los títulos y autores más recurrentes en aquella época como las materias más prolíficas.

- Rastrear las lenguas empleadas en los textos que se deseaban imprimir.

- Confirmar si todos aquellos impresos para los que se solicitaba la licencia de impresión terminaron publicándose o no.

Todo ello, en definitiva, contribuirá a la obtención de una visión más completa del entramado editorial que caracterizó a la Navarra de finales del Antiguo Régimen. Más si tenemos en cuenta que se trata de un escenario, como son las primeras décadas del siglo XIX, caracterizado por la llegada de nuevos tiempos en lo que a la imprenta se refiere. Unos cambios que puntualmente también afectarían a nuestro reino, pese a seguir ostentando hasta su extinción en 1841 ciertas facultades sobre la publicación y comercialización de libros, folletos o pliegos dentro de sus fronteras administrativas. 


\section{CONTEXTO POLÍTICO DE UNA ÉPOCA CONVULSA}

No podemos desligar el estudio de la actividad administrativa del Consejo Real de Navarra del contexto político, militar y legal de las últimas décadas del Antiguo Régimen, pues afectó de una manera directa sobre el correcto funcionamiento de dicha institución. La cual se vio permanentemente amenazada por el poder central, tanto en los períodos de absolutismo real como en los años en que rigió la Constitución de 1812. Sin duda, la inestabilidad social y política que caracterizó aquellos años aquejó directamente al Consejo Real, por lo que su contextualización en este período histórico resulta, si cabe, aún más necesaria.

Para comprender este período debemos ser conscientes, en primer lugar, de las consecuencias institucionales que trajo consigo la entrada de los franceses al mando del General D’Armagnac en febrero de 1808. Un hecho que provocó la fuga de muchos de los miembros del Consejo Real, originando la subsiguiente suspensión de sus funciones además de ser sustituido por otro nuevo nombrado por la nueva administración napoleónica. A su vez, como expone García Pérez (2020:130-131), no era menor el peligro que se cernía sobre el régimen navarro como consecuencia de la aprobación en Cádiz de la primera Constitución liberal del Estado español.

Como no podía ser de otra manera, los postulados liberales surgidos de Cádiz no congeniaban con instituciones como el Consejo Real de Navarra. Sin embargo, la ocupación francesa de Pamplona retrasó la entrada en vigor de la Constitución de Cádiz. Sería el 31 de octubre de 1813 cuando el General Casan se vio obligado a rendirse. De este modo, el acto solemne de jura de la Constitución de Cádiz se produjo el 13 de noviembre en la plaza del Castillo (2014:168). A partir de ese momento, y hasta la restauración absolutista de Fernando VII, Navarra estuvo sujeta a las disposiciones marcadas por la Constitución de 1812, por lo que la permanencia de una institución como el Consejo Real que seguía patrones del Antiguo Régimen se hacía inviable. De todos modos, el retorno de Fernando VII y la promulgación de su célebre Decreto de 4 de mayo de 1814 restauró el régimen monárquico anterior a 1808, por lo que en Navarra se restablecieron todas sus instituciones.

En consecuencia, el triunfo del Antiguo Régimen sobre el constitucionalismo liberal trajo consigo la restitución del Consejo Real de Navarra y el resto del entramado institucional (1994:443). Si bien unos años después la sublevación de Riego el 1 de enero de 1820 en Cabezas de San Juan volvía a eliminar todo el régimen foral. La llegada del conocido como Trienio Liberal ocasionó la sustitución de las instituciones navarras por otras que hallaban su legitimidad en la Constitución de 1812. Sería únicamente tras el enfrentamiento entre realistas y liberales cuando se volvió a reinstaurar el reino y sus instituciones en abril de 1823. Por tanto, nuevamente el Consejo Real volvía a tener actividad.

No obstante, el ocaso que se cernía sobre el régimen institucional navarro se acrecentó en los últimos años del reinado de Fernando VII. Comenzaron a aparecer 
en la escena política realistas ilustrados y algunos afrancesados que preparaban la transición hacia el futuro régimen liberal. Después, la muerte de Fernando VII en 1833 y la posterior contienda militar aligerarían el tránsito entre el Antiguo Régimen y el nuevo Estado constitucional. Hasta entonces el Consejo Real de Navarra había ido luchando por su supervivencia, pero a partir de entonces entraría irremediablemente en la fase de su extinción final. Un proceso que culminaría con la conocida como Ley Paccionada del 16 de agosto de 1841, momento en que Navarra deja de ser un reino para pasar a ser una provincia española.

\section{EL CONSEJO REAL EN MATERIA DE IMPRENTA}

Como vemos, resulta crucial conocer el contexto político, aunque no menos relevante será desentrañar el papel que ostentó el Consejo Real durante estas décadas con los cambios legales que se fueron experimentando en materia de imprenta. Debemos tener en cuenta que hasta principios del XIX las instituciones del reino, entre ellas el Consejo Real, llegaron intactas, por lo que en materia de imprenta seguía rigiendo para nosotros el modelo que Felipe II había instaurado con su Pragmática en $1558^{1}$. Desde entonces era el Consejo Real de Navarra el encargado de conceder los privilegios de edición y de otorgar las respectivas licencias de impresión, así como de controlar que no entraban obras publicadas fuera del reino.

De este modo, el Consejo Real de Navarra se encargó a partir de 1558 de supervisar y controlar el proceso editorial en estas tierras. Unas funciones que, como testimonia Sesé Alegre ${ }^{2}$, perduraron hasta bien entrado el siglo XIX y que nos han dejado evidentes rastros de su actividad. Como muestra de ello tendríamos los expedientes de autorización de impresiones que se conservan en el Archivo General de Navarra entre 1801-1831. Antes de ello no se conserva ningún testimonio documental de este calibre, simplemente en el siglo XVIII (entre 17591787) hay un listado de las licencias concedidas a un total de 124 libros impresos en el reino ${ }^{3}$. Desde mi punto de vista, no quiere decir esto que el Consejo Real no cumpliese con sus funciones o que fuese descuidado en su ejercicio, sino que únicamente no se ha conservado testimonio documental de dichos procedimientos administrativos, como sí ha ocurrido en el caso del Archivo Histórico Nacional. No obstante, a imagen y semejanza del Consejo de Castilla en Navarra nos encontramos con que fue el Consejo Real quien asumió las competencias en relación con el control de la imprenta y el mercado editorial.

No obstante, el convulso siglo XIX trajo consigo una constante inestabilidad política que terminó afectando al correcto funcionamiento administrativo del

\footnotetext{
${ }^{1}$ Merece la pena consultar las apreciaciones de Salcedo Izu, 1982: 645-677.

${ }^{2}$ Sesé Alegre, 1994: 443.

${ }^{3}$ Aspecto advertido y tratado por Itúrbide Díaz, 2007: 70.
} 
Consejo Real en materia de imprenta ${ }^{4}$. Uno de los primeros sucesos que debemos destacar llegaría de la mano de Carlos IV, cuando el monarca decidió centralizar la censura en un mismo órgano para que éste se dedicara en exclusiva a esa labor. De esta manera, según Reyes Gómez (2000: 706), se facilitaría la publicación de obras útiles y el rechazo de las inútiles y perjudiciales. Aquel órgano será el conocido como Juez de Imprentas, independiente del Consejo y del Juzgado de imprentas. El 11 de abril de 1805 la Real Orden disponía que la figura del Juez de Imprentas pasaba a ser la autoridad competente para todas las imprentas y librerías.

Una situación en la que cabe mencionar a Juan Antonio Melón, quien entre sus iniciativas propuso que Navarra se unificase del todo con el resto de territorios hispanos, por lo que deseaba que el Consejo Real perdiese su facultad para conceder licencias. Sin embargo, su actitud se topó con la oposición de Ramón Giraldo, quien como subdelegado de imprentas en Navarra hizo ver a Melón que la concesión de licencias era a cargo del Consejo Real de Navarra, sin atenerse al de Castilla ni a otro juez ${ }^{5}$. Pese a ello, lo cierto es que entre 1806 y 1808, antes de la invasión francesa, no se conservan expedientes de autorización de impresiones en el Archivo General de Navarra, por lo que pudo deberse al cumplimiento de esta disposición finalmente.

Bien es cierto que el 27 de marzo de 1808 fue Fernando VII quien suprimió el Juzgado de imprentas, devolviendo al Consejo de Castilla sus anteriores atribuciones en este asunto. Cabe pensar que sucedió igual para el caso navarro, aunque poco después se produciría la ocupación francesa del reino, por lo que el Consejo Real dejó de tener un funcionamiento normal en lo que a la concesión de licencias de impresión se refiere. Como ya se ha indicado, hasta octubre de 1813 la ciudad de Pamplona estuvo bajo el dominio francés. Sin embargo, tras la liberación del reino no se restauró el modelo anterior, pues se instauró el modelo aprobado en Cádiz un año antes. De este modo, gracias a la Constitución de 1812 reinaba la libertad de escribir, imprimir y publicar sin necesidad de licencia, por lo que el Consejo Real no tenía ninguna potestad administrativa ${ }^{6}$.

Sería a mediados de 1814 cuando Fernando VII decidiese derogar la obra constitucional y legislativa de las Cortes gaditanas. Así a través del Decreto de mayo de ese año se restablecía el sistema anterior a 1805. Una situación que puede comprobarse a través de las peticiones de licencias de impresión que se registraron, lo que demuestra que el Consejo Real comenzó a funcionar nuevamente. En definitiva, se produjo la vuelta a un modelo anterior que

\footnotetext{
${ }^{4}$ Como es obvio no sólo afecto a Navarra, sino también a Castilla. Para el caso castellano puede consultarse el estudio de Benito Ortega, 2011: 184-184.

${ }^{5}$ Esta polémica ya fue estudiada por Reyes Gómez, 2000: 713-714; Domergue, 1977: 213-214 y García Martín, 2003: 247.

${ }^{6}$ Sobre la libertad de imprenta decretada en la Constitución de Cádiz pueden consultarse distintos trabajos: Navarro Marchante, 2011: 349; García Pérez, 1998: 201; Reyes Gómez, 2000: 723; Marcuello Benedicto, 1999: 67; Gil Novales, 2012: 403.
} 
nuevamente sería sustituido con el pronunciamiento de Riego. Así en 1820 se restableció el sistema constitucional de 1812, aunque se formuló una nueva Ley de Imprenta que marcó el tono del Trienio Liberal ${ }^{7}$. Como podemos ver, entre 1821 y 1822 el Consejo Real dejó de tener actividad, y ya en 1823 registra nuevamente peticiones de licencia como consecuencia del fin del modelo liberal y la restauración fernandina.

Gráfico 1. Evolución del número de expedientes de autorización (1801-1831)

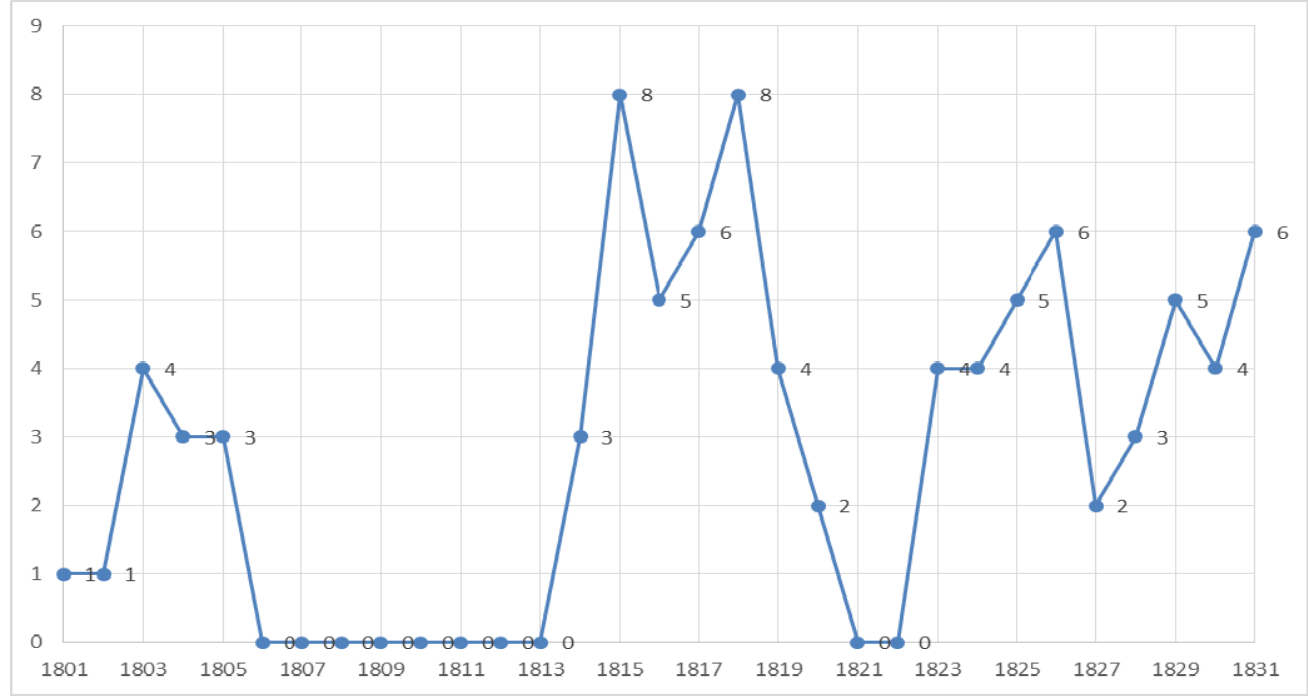

A partir de entonces, como puede apreciarse, el Consejo Real registró una destacada actividad administrativa que se verá interrumpida a finales de 1831, momento en que cesan los datos relativos a expedientes de autorización de impresiones. Resulta lógico pensar que después de esta fecha, sobre todo a partir de 1833, no se conserven registros porque el reino se vio sumido en la I Guerra Carlista y, tras la contienda, llegaría en 1841 la extinción del reino, aunque ya antes deberíamos tener en cuenta que desde 1836 se estaba gestando el regreso a las normas promulgadas durante el Trienio Liberal y que verían la luz en la Ley de Imprenta del 15 de marzo de 1837 (Pérez Juan, 2006: 701). Por tanto, es normal que los testimonios documentales fenezcan en 1831, si bien únicamente llama la atención que no haya expedientes relativos a los años 1832 y 1833.

\footnotetext{
${ }^{7}$ Véase el estudio de Marcuello Benedicto.
} 


\section{EXPEDIENTES DE AUTORIZACIÓN DE IMPRESIÓN DE LIBROS}

Una vez esbozado el panorama legal que afectó al funcionamiento del Consejo Real y a la puesta en marcha de su actividad administrativa en materia de imprenta, pasamos a analizar los 87 expedientes de autorización de impresiones conservados en el Archivo General de Navarra. No obstante, antes de nada, considero oportuno destacar que la documentación administrativa existente sobre asuntos de imprenta es bastante escasa si se compara con la que hay en el Archivo Histórico Nacional. No cabe duda de que la actividad del Consejo Real de Navarra fue mucho más modesta en lo que se refiere a la industria editorial que el ritmo frenético que se registró en el Consejo de Castilla. Además, como expone Itúrbide Díaz (2007: 69), en nuestro caso no asistimos al desarrollo de un conjunto de normas relativas a temas editoriales, lo que hace que nos encontremos ante una gestión administrativa un tanto endeble.

En consecuencia, esta realidad ayudaría a explicar los exiguos funcionarios y la escasa especialización de los mismos a la hora de encargarse de controlar todo aquello relacionado con la imprenta en el reino. Asimismo, del análisis de los expedientes se desprende la sensación de un Consejo Real que no tuvo entre sus funciones prioritarias llevar a cabo una efectiva fiscalización de la industria tipográfica. Más bien parece que se trató de una preocupación puntual que se desarrolló de forma rutinaria cuando había que resolver la concesión de licencias de impresión, momento en el que se encargaba de designar censores y revisores para decidir si concedía o no la mencionada licencia.

Dejando a un lado la actitud más o menos diligente del Consejo Real en materia de imprenta, lo que nos manifiestan los expedientes estudiados es que en 86 ocasiones, prácticamente en el $100 \%$ de los casos, lo que se dirime es la petición de una licencia para la impresión de un texto, pues tan sólo hay un caso de los 87 analizados en donde se trata de una petición para aumentar el precio de venta de una obra de gran demanda, que no es otra que el Arte de Nebrija. Pero de estas 86 peticiones de licencia, ¿cuántas fueron atendidas de forma positiva por el Consejo Real? Comprobamos que fueron 75 los casos en que la licencia de impresión terminó concediéndose, lo que supone un $87 \%$ de los expedientes conservados. Sin embargo, en el restante $13 \%$ de las ocasiones apreciamos dos opciones: la no concesión de la licencia como consecuencia de una negativa del Consejo o la finalización del expediente administrativo sin cerrar el trámite, lo que vendría a suponer una licencia no concedida igualmente.

Tabla 1. Licencias solicitadas (1801-1831)

\begin{tabular}{|c|c|}
\hline Licencias & Número casos \\
\hline Concedidas & 75 \\
\hline No concedidas & 11 \\
\hline Total & 86 \\
\hline
\end{tabular}


Ahora bien, ¿̇todos los textos que piden licencia para ser impresos y que fueron autorizados por el Consejo terminaron siendo publicados? Se han contabilizado un total de 61 textos publicados de las 86 peticiones que se conservan, por lo que como se aprecia no todas las peticiones de licencia que fueron resueltas de forma positiva originaron la edición de aquellos textos. Asimismo, hay expedientes que no se cerraron con la concesión de dicho trámite administrativo, pero dichas obras sí terminaron siendo publicadas. A continuación mostraremos en el siguiente listado los impresos que vieron la luz tras la concesión o no de la licencia por parte del Consejo Real de Navarra. En todos ellos se indica el título junto al año de edición y la imprenta pamplonesa donde se llevó a cabo la impresión, así como una referencia numérica extraída de los distintos repertorios o catálogos bibliográficos que han sido consultados.

- Biblioteca nueva de los escritores aragoneses. Joaquín Domingo: 1802. (CCPB, 000078106-1).

- Manifiesto sobre el estado de la casa de misericordia. s. n.: 1802. (Pérez Goyena, 3528).

- Cartilla de Terceros Seráficos: en que se contiene la Regla que dio a sus Hijos Terceros el Seráfico Patriarca. José de Rada: 1803. (Pérez Goyena, 3563).

- Libro de la oración y meditación. Viuda de Longás: 1804. (Palau, 107463).

- Cristau-dotriña, ceñetan eracusten baitire gure fede sanduco gauzaric bearrénac. José de Rada: 1804. (CCPB, 000802933-4).

- Compendio moral salmaticense. José de Rada: 1804. (Pérez Goyena, 3702).

- Disertación a favor de la Suprema Autoridad del Romano Pontífice sobre todos los Concilios. Joaquín Domingo: 1815. (Pérez Goyena, 4131).

- El soldado católico en guerra de religión: carta instructiva ascético histórico-política. Joaquín Domingo: 1815. (Pérez Goyena, 4119).

- Sermón que en viernes tercero de cuaresma predicó al rey nuestro señor en su real capilla el carmelita Fray José del Salvador. Joaquín Domingo: 1815. (Pérez Goyena, 4152).

- Grande imperial, y real mojiganga. Imprenta de Longás: 1815. (Pérez Goyena, 4041).

- Sermón que en la solemne función de acción de gracias a Dios por el feliz restablecimiento de la ínclita religión de la Compañía de Jesús. Joaquín Domingo: 1815. (Pérez Goyena, 4132).

- Oraciones y meditaciones para asistir con devoción y respeto al santo sacrificio de la misa. José Domingo: 1815. (Pérez Goyena, 4113).

- Fueros del Reyno de Navarra: desde su creación, hasta su feliz unión con el de Castilla. Paulino Longás: 1816. (Pérez Goyena, 4138).

- Sermón del glorioso mártir e inquisidor San Pedro Mártir de Verona. Joaquín Domingo: 1816. (FSS, 10357-5636). 
- Compendio de las alabanzas, prodigios, finezas y gracias que la gloriosa virgen y mártir santa Bárbara ha obrado con sus devotos. Joaquín Domingo: 1816. (Pérez Goyena, 4218).

- Jaungoicoaren amar aguindubeetaco lehengo bosteen icasiquizunac. Viuda de José de Rada: 1816. (Pérez Goyena, 4212).

- Euscal-Errijetaco olgueeta ta dantzeen neurrizco-gatz-ozpinduba. Joaquín Domingo: 1816. (Pérez Goyena, 4211).

- Jaungoicuaren amar aguindubeetaco azqueneco bosteen icasiquizunac. Viuda de José de Rada: 1817. (Pérez Goyena, 4212).

- Gramática latina en castellano dispuesta por el R.P. Fr. José Carrillo. Imprenta de Longás: 1817. (Pérez Goyena, 4217).

- Dictamen del gremio y claustro de la universidad de Salamanca sobre la consulta hecha por los tres Estados del Reyno de Navarra, acerca del comercio del comercio de granos. José Domingo: 1817. (Pérez Goyena, 4244).

- Discurso en que se manifiesta que el oficio de cortador de carne es una honesta ocupación que no infama. Joaquín Domingo: 1817. (Pérez Goyena, 4243).

- Libro de la oración: en la cual se trata de la consideración de los principales misterios de nuestra fe y de las partes y doctrina para la oración. Xavier Gadea: 1818. (CCPB, 000855995-3).

- Observaciones sobre la octava edición de la Ortografía castellana por la real Academia española. José Domingo: 1818. (Pérez Goyena, 4266).

- Presentación afectuoso sentimiento que la M. N. y M. L. ciudad de Pamplona, cabeza del reino de Navarra consagró a la memoria de la señora Isabel Francisca de Braganza y Borbón, reina de las Españas. Imprenta de Longás: 1819. (Pérez Goyena, 4279).

- Cuaderno de las Leyes y agravios reparados á suplicación de los tres Estados del Reino de Navarra en sus cortes Generales, celebradas en la ciudad de Pamplona los años 1817 y 1818. Imprenta de Longás: 1819. (Pérez Goyena, 4288).

- Eleisaco zazpi sacramentuben icasiquizunac. Viuda de José de Rada: 1819. (Pérez Goyena, 4213).

- Instrucción al público o apología de la conducta que han observado los frailes de San Francisco de Pamplona. Xavier Gadea: 1820. (Pérez Goyena, 4473).

- El alma elevada á Dios, por las reflexiones y sentimientos. Imprenta de Longás: 1820. (Pérez Goyena, 4330).

- La verdad contra el error y desengaño de incautos. s. n.: 1823. (Pérez Goyena, 4774).

- Navarros; La generosidad benéfica del augusto Monarca de la Francia, las estraordinarias fatigas, servicios y denuedo de sus beneméritas tropas, los trabajos y constancia de los Batallones de nuestra División y del Regimiento del Infante Don Carlos. s. n.: 1823. (Pérez Goyena, 4770). 
- Instrucciones prácticas relativas a varios puntos litúrgicos que deben ser ejecutados por los párrocos y demás sacerdotes. Viuda de Rada: 1823. (Pérez Goyena, 4755).

- Septenario en honor del glorioso San José. Francisco Erasun y Rada: 1824. (CCPB, 000572322-1).

- Valerosos soldados cristianos. Xavier Gadea: 1824. (Pérez Goyena, 4825).

- Análisis Químico y propiedades medicinales del agua mineral llamada del batueco. Ramón Domingo: 1824. (López Piñeiro, 1359).

- Ensayo sobre el principio generador de las constituciones políticas y demás constituciones humanas. Xavier Gadea: 1825. (Pérez Goyena, 4875).

- Los don Quijotes del siglo diez y nueve ó sea Historia de las revoluciones de los Filósofos modernos en España. Francisco Erasun y Rada: 1825. (Pérez Goyena, 4878).

- Historia de la guerra de la división real de Navarra contra el intruso sistema llamado constitucional y su gobierno revolucionario. Xavier Gadea: 1825. (Pérez Goyena, 4876).

- Elementos teórico-prácticos de Aritmética para instrucción de los niños. Francisco Erasun y Rada: 1826. (Pérez Goyena, 4936).

- Regla de la Orden, que para sus hijos Terceros Seglares instituyó San Francisco. Xavier Gadea: 1826. (Pérez Goyena, 4931).

- Cristau-doctrina. Aita Gaspar Astetec erdaraz escribitua eta orai escuaraz publicatzen duena, cembait gauza aumentaturic. Xavier Gadea: 1826. (Pérez Goyena, 4903).

- Cartas críticas sobre la nueva Historia de la Iglesia y Obispos de Pamplona. Francisco Erasun y Rada: 1826. (Pérez Goyena, 4911).

- Plan muy instructivo a los maestros de primeras letras acerca de los conocimientos que abraza su profesión, y modo de comunicarlos con orden, método y claridad a sus discípulos. Francisco Erasun y Rada: 1827. (Pérez Goyena, 4982).

- Nuevo libro segundo de los niños: muy útil y metódico para facilitarles la enseñanza de la lectura. Francisco Erasun y Rada: 1827. (Pérez Goyena, 4984).

- Constituciones Fratrum Discalceatorum Beatissiae Virginis Mariae de Monte Carmelo. Francisco Erasun y Rada: 1827. (Pérez Goyena, 4948).

- Guía de colmeneros o tratado práctico de Abejas. Francisco Erasun y Rada: 1827. (Pérez Goyena, 4978).

- Compendio de la Historia de la aparición de San Miguel de Excelsis y de su antiquísimo santuario en el monte de Aralar. Francisco Erasun y Rada: 1828. (Pérez Goyena, 5010).

- Novena a la seráfica virgen doctora mística santa Teresa de Jesús. Xavier Gadea: 1828. (Pérez Goyena, 5011).

- Mina preciosísima que presenta á las almas para que á poca costa abunden en riquezas espirituales un devoto individuo de la Venerable y Santa 
Congregación de la augustísima Trinidad. Francisco Erasun y Rada: 1828. (Pérez Goyena, 5018).

- Relación sencilla de las funciones de exequias que el ayuntamiento de la M.N.M.L.Y.M.H. ciudad de Pamplona, cabeza del reino de Navarra, ha celebrado por la reina Doña María Josefa Amalia. Francisco Erasun y Rada: 1829. (Pérez Goyena, 5025).

- Cuaderno de las leyes y agravios reparados a suplicación de los tres estados del reino de Navarra en sus cortes generales celebrados en la ciudad de Pamplona los años 1828 y 1829. Imprenta de Longás: 1829. (Pérez Goyena, 5039).

- Discurso que leyó el Doctor D. Jaime Salvá en la apertura del Real Colegio de Medicina, Cirugía y Farmacia del Reino de Navarra. Francisco Erasun y Rada: 1829. (Pérez Goyena, 5063).

- Despertador eucaristico y dulce convite para que las almas enardecidas en el dulce amor de Jesus sacramentado. Francisco Erasun y Rada: 1829. (Pérez Goyena, 5036).

- Oración fúnebre que en las solemnes exequias que el 29 de octubre se celebraron en la Iglesia del Santo Hospital General por la Junta de Gobierno. Francisco Erasun y Rada: 1829. (Pérez Goyena, 5021).

- Periódico mensual de Medicina y Cirugía. Francisco Erasun y Rada: 1830. (Pérez Goyena, 5128).

- Receta o método curativo de la enfermedad de tiña. Francisco Erasun y Rada: 1830. (Pérez Goyena, 5076).

- El observador en la diversión de caza y escopeta de pistón. Francisco Erasun y Rada: 1830. (Pérez Goyena, 5144).

- Elementos de geografía universal: arreglados para la enseñanza de las señoritas del Colegio de Pamplona. Imprenta de Longás: 1830. (Pérez Goyena, 5126).

- Escudete-engerto o nuevo método de engertar de escudete los troncos de árboles, arbolillos, arbustos de flores y frutas. Francisco Erasun y Rada: 1831. (Pérez Goyena, 5165).

- La mitología por preguntas y respuestas para la instrucción de la juventud. Francisco Erasun y Rada: 1831. (Pérez Goyena, 5185).

- Plan y reglamento general para las escuelas de primeras letras del Reino de Navarra. Francisco Erasun y Rada: 1831. (Pérez Goyena, 5199).

- Catecismo histórico o compendio de la Historia Sagrada y de la Doctrina Cristiana para la instrucción de los niños con preguntas y respuestas, y lecciones seguidas a fin de leerlas en las escuelas. Imprenta de Longás: 1832. (Pérez Goyena, 5227).

A su vez, tendríamos las 25 obras restantes que no terminaron siendo editadas en el reino -o de las que al menos no se conserva ningún ejemplar- pese a que tenemos el expediente de autorización. En algunos casos se trataría de textos que recibieron una censura negativa, o que ni siquiera llegaron a recibir el permiso del 
Consejo Real para ser publicados, pese a que también hay ocasiones en que se trata de publicaciones que no vieron la luz aun habiéndoseles concedido la licencia de impresión. En estos casos nos encontramos bien con editores que deben renunciar por falta de dinero a la edición de determinados textos o con autores que finalmente deciden no publicar sus textos por resultar polémicos, como le sucedió a José María de Zuaznavar en 1824 con su obra Las murmuraciones contra el Gobierno, quien debido a "nuevas circunstancias que han sobrevenido le han hecho variar su idea y no trata que se dé al público dicho discurso"․ . Dicho esto, entre los textos que no se editaron encontramos los siguientes:

- Devota preparación de nueve días para celebrar la fiesta de la Santa Madre Teresa de Jesús, doctora Mística y fundadora de los carmelitas descalzos. 1801.

- Conclusiones del Convento de los Mercedarios. 1803.

- Constituciones Sinodales del Obispado de Pamplona. 1804.

- Disertación de los grados y certidumbre de la Medicina. 1805.

- Cartel del Hospital de la Misericordia. 1805.

- Elogio del General Gravina. 1805.

- Proclama de Aragón. 1814.

- Carta de S. Santidad Pío Papa VII a D. Justo Pastor Pérez. 1815.

- Glorias de Pamplona. 1815.

- Principios de Gramática y Ortografía castellana. 1815.

- Compendio de la autoridad de las dos potestades. 1818.

- Mística ciudad de Dios. 1816.

- De los principios o fundamentos de la ortografía. 1817.

- Oraciones y meditaciones para asistir con devoción al Santo Sacrificio de la Misa y recibir los Santos Sacramentos. 1818.

- Sentencia del Tribunal Real del Departamento de Tarn. 1818.

- De las reglas para la enseñanza de latinidad. 1818.

- La lógica de Condillac. 1818.

- Informe Fiscal de la Real Audiencia de Canarias. 1818.

- Curaciones efectuadas por el médico Ignacio Páramo. 1820.

- De la constitución de las Cortes de España. 1823.

- Las murmuraciones contra el Gobierno. 1824.

- Lecciones elementales de anatomía descriptiva. 1825.

- Tratado filosófico y práctico sobre los cabellos de la especie humana. 1826.

- Consejos de una madre a su hija sobre la educación. 1831.

- Anuncio del establecimiento de un baño de vapor de José Mirapais. 1831.

Pese a que como hemos podido apreciar no todas las concesiones de licencia terminaron con la publicación de los respectivos textos, lo realmente interesante es

${ }^{8}$ Archivo General de Navarra (AGN), Tribunales Reales. Papeles Varios, Legajo 14, núm. 56, fol. 2r. 
que esta fuente documental nos permite reconstruir el procedimiento administrativo y el funcionamiento del Consejo Real en materia de imprenta. Asimismo, como ya ha sido advertido nos muestra aspectos clave para entender la industria editorial local a principios del siglo XIX.

Así, por ejemplo, podemos trazar un análisis numérico del total de publicaciones que se editaron en Navarra por estas fechas y compararlo con el número de expedientes de autorización de impresiones que se conservan en el Archivo General de Navarra. Si cogemos como punto de partida los años en los que el Consejo Real tuvo actividad en materia de imprenta (1801-1805, 1814-1820 y 1823-1831) comprobamos -sin tener en cuenta la impresión de cédulas, bandos o circulares- que según el Ensayo de bibliografía navarra de Pérez Goyena se publicaron 312 impresos y si nos basamos en los resultados arrojados por el CCPB serían 208. De este modo, en esos 21 años tendríamos los expedientes de autorización de 61 publicaciones, lo que supondría un 20\% de las impresiones si tomamos como referencia los datos ofrecidos por Pérez Goyena y si siguiésemos el CCPB como muestra aumentaría al $29 \%$ de los textos publicados cuando el Consejo Real de Navarra ostentaba sus competencias en asuntos editoriales.

En definitiva, sean pocos o muchos porcentualmente hablando, lo reseñable es que esta muestra nos permite inferir datos de suma relevancia para reconstruir la historia del libro y de la imprenta en el reino de Navarra a finales del Antiguo Régimen. Más si tenemos en cuenta que se trata de los únicos testimonios documentales conservados para el estudio de las facultades del Consejo Real en materia de imprenta desde que en 1558 entrase en vigor el modelo administrativo diseñado por Felipe II.

\section{PETICIÓN DE IMPRESIÓN: EL PROCEDIMIENTO ADMINISTRATIVO}

Al margen de estos datos, vamos a centrarnos ahora en los distintos procedimientos administrativos que debían ser superados para que el Consejo Real dictaminase que un texto podía ser impreso y comercializado en aquella época. Como es obvio, el primer paso que debía emprender cualquier texto para ser publicado era remitir una solicitud de licencia con el original manuscrito al Consejo Real. Bien es cierto que los libros de carácter religioso debían obtener primero el permiso del obispado pamplonés ${ }^{9}$.

Por lo general, el modo de iniciar el trámite administrativo era a través de un procurador que actuaba en nombre del editor de la obra. Era el momento de explicar los posibles motivos que habían llevado a elaborar un texto, para lo que solían hacer mención al interés de la sociedad o a la necesidad por transmitir cierta

\footnotetext{
${ }^{9}$ Como acertadamente lo señala en su libro Itúrbide Díaz, 2007: 71.
} 
información a la población. Así Joaquín de Barricarte en 1801 señalaba que los carmelitas descalzos querían sacar a la luz "un libro en octavo manoescrito para celebrar la fiesta de Santa Teresa de Jesús”, con la finalidad “de que la comunidad, mi parte, pueda valerse de ella en las festividades anuales de dicha Santa o en aquellas partes que la devoción les mueve a lo mismo"10. Ensalzar el valor pedagógico del texto era otro de los métodos más usuales, como por ejemplo hizo Isidro Ferrer en 1814 al advertir que el impresor Joaquín Domingo "desea dar a la imprenta la carta instructiva escrita por el Padre Fray Diego José de Cádiz”" ${ }^{\text {" A su }}$ vez, mejorar la instrucción de los fieles solía resultar clave entre los motivos escogidos, por lo que Antonio de Corres no dudaba en señalar que Fray Bartolomé de Santa Teresa "con el objeto de la mejor instrucción de los fieles ha compuesto un libro de Pláticas doctrinas sobre los cinco primeros mandamientos de la ley de Dios en idioma vascongado"12.

Sin embargo, había otras motivaciones detrás de aquellas peticiones de impresión. Entre ellas podríamos destacar, por ejemplo, el interés por el desarrollo de la actividad industrial en el reino. Así Matías Antonio de Goicoa decía que la obra: Guía de colmeneros o tratado práctico de abejas, pretendía "fomentar la industria en la ciudad de las abejas"13. Junto a este caso, otras veces la necesidad de defenderse de ataques vertidos en otro impreso eran la excusa para solicitar la impresión de una obra que contraatacaba. De este modo, Javier Sánchez mostraba que Ignacio Rufino Fernández había compuesto cuatro cartas críticas con la nueva Historia de la Iglesias y Obispos de Pamplona, impresa en Madrid en 1820, pues en ella se "demuestra con toda evidencia la ignorancia, la parcialidad e infidelidad del historiador sobre algunos hechos concernientes a dicha Santa Iglesia y su Cabildo, y se rebaten victoriosamente las calumnias que en ella se hallan esparcidas con testimonios auténticos sacados del archivo"14.

Por último, el interés por una obra hizo que algunos impresores y libreros hiciesen mención a su escasez a la hora de solicitar una reimpresión. Así fue como Antonio Zarraluqui en nombre de José Domingo, impresor y librero pamplonés, indicaba que "son ya muy pocos los que se encuentran", en referencia a las obras: Oración y meditación y los Principios de Gramática y Ortografía castellana, por lo que "desea mi parte por su facultad reimprimirlos puesto no puede haber motivo racional para lo

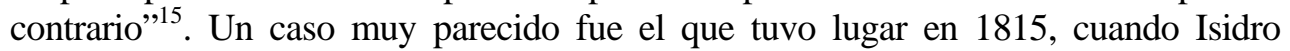
Ferrer mencionaba que Joaquín María Domingo quería editar un sermón relativo al

\footnotetext{
${ }^{10}$ AGN, Tribunales Reales. Papeles Varios, Legajo 14, núm. 3, fol. 21r.

${ }^{11}$ AGN, Tribunales Reales. Papeles Varios, Legajo 14, núm. 17, fol. 1r

${ }^{12}$ AGN, Tribunales Reales. Papeles Varios, Legajo 14, núm. 30, fol. 3r.

${ }_{13}$ AGN, Tribunales Reales. Papeles Varios, Legajo 14, núm. 71, fol. 1r.

${ }^{14}$ AGN, Tribunales Reales. Papeles Varios, Legajo 14, núm. 69, Fol. 52.

${ }^{15}$ AGN, Tribunales Reales. Papeles Varios, Legajo 14, núm. 21, fol. 1r
} 
restablecimiento de la Compañía de Jesús "porque muchos la piden y desean tenerla en su poder porque en este reino escasean mucho los exemplares" 16 .

Figura 1. Original manuscrito: Elogio del General Gravina (1815)

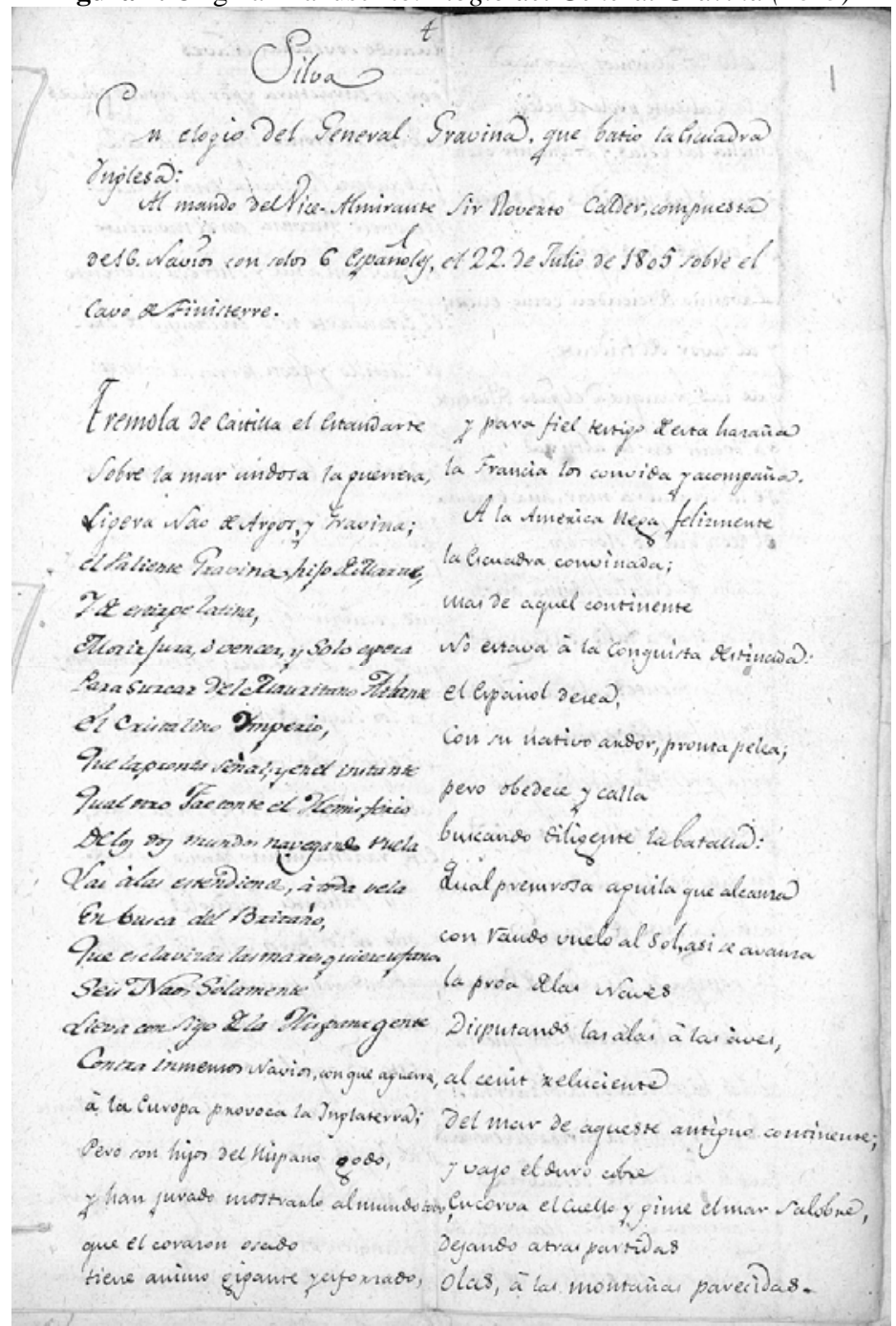

AGN, Tribunales Reales. Papeles varios, legajo. 14, núm. 14, fol. 1r.

${ }^{16}$ AGN, Tribunales Reales. Papeles Varios, Legajo 14, núm. 25, fol. 1 r. 
Figura 2. Original manuscrito: Elementos teórico-prácticos de Aritmética (1825)

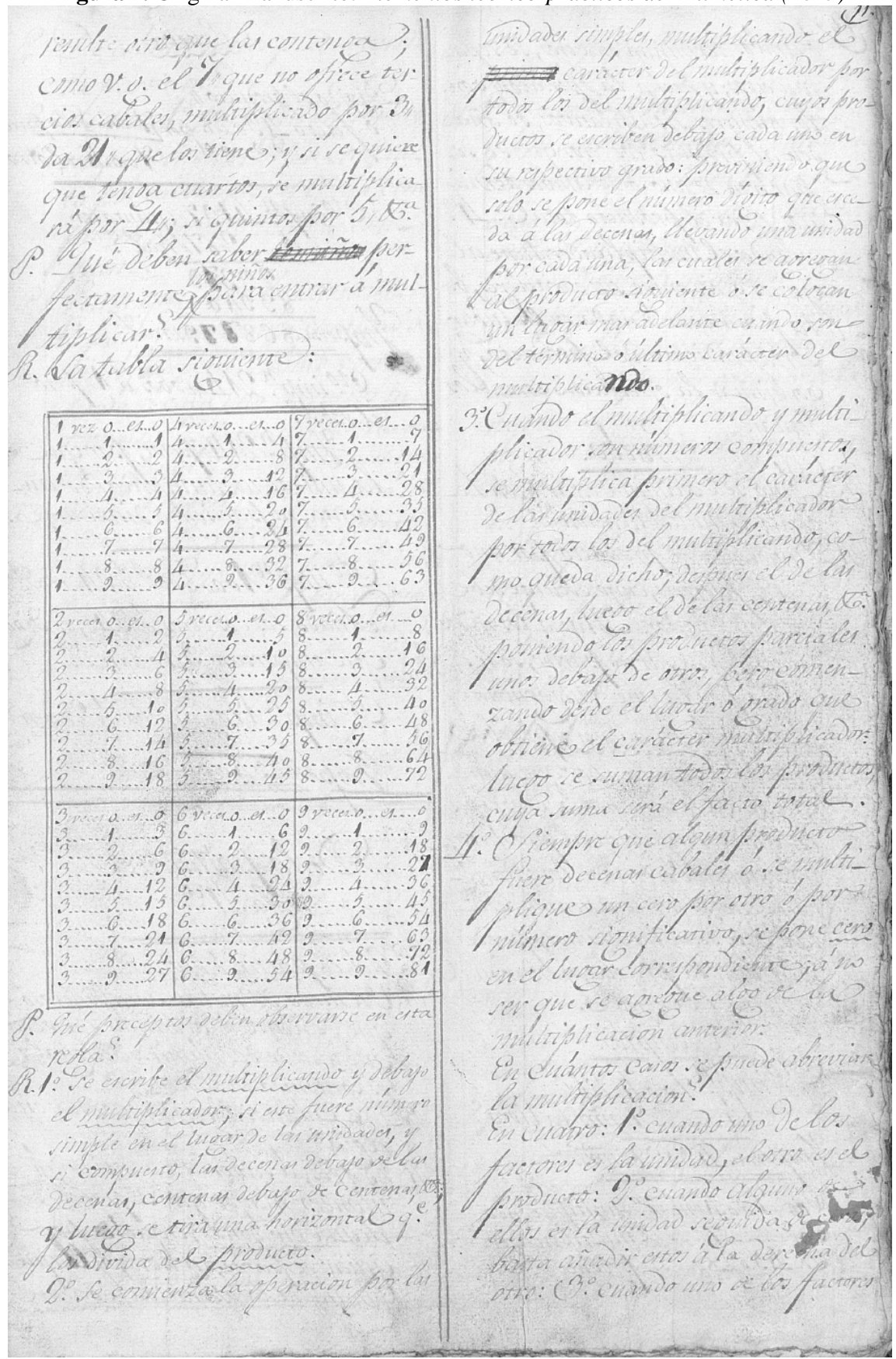

AGN, Tribunales Reales. Papeles varios, legajo. 14, núm. 62, fol. 11r. 
Vistas las distintas causas o motivaciones que solían ser reflejadas en la petición de licencia por parte de los interesados, cabe afirmar que su intención no era otra que reflejar la calidad, interés, necesidad y éxito del texto. De esta manera, a través de las peticiones se pretendía resaltar la originalidad e importancia de la obra que se quería editar para que así las autoridades fuesen más benévolas. Lo cierto es que una vez presentada dicha petición junto al original el Consejo Real acordaba que se pasase dicho texto manuscrito a la censura.

Tabla 2. Aplicación censura (1801-1831)

\begin{tabular}{|c|c|}
\hline Censura & Número casos \\
\hline Se aplica & 50 \\
\hline No se aplica & 36 \\
\hline Total & 86 \\
\hline
\end{tabular}

Tabla 3. Tipo de censura (1801-1831)

\begin{tabular}{|c|c|}
\hline Censura aplicada & Número casos \\
\hline Positiva & 48 \\
\hline Negativa & 2 \\
\hline Total & 50 \\
\hline
\end{tabular}

Después, tras dictaminar el censor que iba a analizar el texto por orden del Consejo Real se iniciaba la censura, que podía terminar de dos maneras: aprobando la obra o reprobándola. En este último caso, cuando la censura era negativa, el libro ni siquiera salía al mercado para ser comprado porque contenía ideas o conceptos contrarios a la Fe Católica o a las regalías de los monarcas ${ }^{17}$. Cabe conjeturar que posiblemente dadas las peculiaridades de un reino tan pequeño y escasamente relevante en el mercado editorial no existiese una actividad denegatoria muy ajetreada. Lo cierto es que de los 86 expedientes relativos a peticiones de licencia de impresión, 50 de todos ellos recogen prácticas censorias (58\%), dentro de las cuales en 48 ocasiones la censura fue positiva (96\%) frente a 2 casos en los que resultó negativa (4\%).

A simple vista, constatamos que un $42 \%$ de los textos no superaron censura alguna $\mathrm{o}$, al menos, dicho procedimiento no dejó testimonio manuscrito en los expedientes que se han conservado. De lo que no hay duda es que hubo obras que se publicaron inmediatamente después de recibir el permiso del Consejo Real, aunque no existen pruebas de haber superado la respectiva censura.

Dicho esto, y volviendo al ejercicio práctico de la censura, cabe resaltar que habitualmente -aunque no siempre- solía recaer ésta en clérigos pamploneses por dos razones, tanto por sus competencias intelectuales en materia de ortodoxia religiosa y filosófica, principalmente, como por la disponibilidad de tiempo para

\footnotetext{
${ }^{17}$ Véanse a este respecto las apreciaciones realizadas por Bragado Lorenzo (2004: 573); Álvarez Cora (2003: 290).
} 
acometer aquellos encargos. Debemos tener en cuenta que el trabajo de censor no estaba remunerado, a lo sumo podían aspirar a recibir como obsequio un ejemplar del libro censurado, por lo que se concebía como un encargo honorífico, así como un reconocimiento de la autoridad y prestigio profesional para el censor ${ }^{18}$. En consecuencia, si tenemos presente que el censor realizaba su cometido de forma gratuita resulta comprensible que algunas veces actuasen con cierta lentitud a la hora de emitir su informe, pese a que por lo general no se solían demorar más de una o dos semanas.

Al margen de estos aspectos puramente formales, si prestamos atención a la actividad de los censores observamos que cuando se considera que la obra no contiene ningún apartado peligroso o dañino se indica que se estima oportuno que se le otorgue la licencia solicitada. Así sucedió, por ejemplo, cuando se les encomendó en 1805 a los médicos Casimiro Moreno y Martín Osácar examinar el libro: Disertación de los grados y certidumbre de la Medicina. Ambos dicen que "habiéndola leído con la más reflexiva atención deducimos no oponerse en cosa alguna a los principios, reglas, preceptos y método de la verdadera medicina”, pues además el autor trata "de ilustrar la experiencia con el raciocinio y ratificar la theoria con la práctica, clavando constantemente los ojos en el seno de la naturaleza apurando sus secretos en el instinto, en las leyes constantes”"19. Debido a ello, "somos de sentir que este escrito no contiene cosa que se oponga a las regalías de su majestad y que se le puede conceder la licencia que solicita para la impresión”20.

Incluso era habitual ensalzar al autor en la censura emitida, como sucede en el Sermón del glorioso mártir e inquisidor San Pedro Mártir de Verona en 1816. En ella el censor señalaba: "Lo he leído con gusto y admiración. Con gusto por la delicadeza y claridad de su estilo, orden y método en su composición. Con admiración por la erudición sublime con que prueba su argumento apoyado en la autoridad de la Sagrada Escritura, Santos Padres e Historia". Por tanto, "no contiene el escrito cosa contraria a nuestra Santa Fe y buenas costumbres"21.

Cosa distinta será cuando el censor encuentre contenidos polémicos o modificables, pues debía indicar los cambios o supresiones a introducir por el solicitante para que la licencia se le pudiese conceder a dicho texto. En 1817 el maestro de latín, Antonio María Francés, recibió el encargo de examinar De los principios o fundamentos de la ortografía, una obra que pese a estar escrita "con exactitud y método" y "su doctrina es conforme a la obra de donde está deducida” tenía alguna parte mejorable. Según el censor "sólo hallo el reparo que en algunos lugares en que trata del uso diferente de la b y de la v, y así mismo de la aplicación

${ }^{18}$ Sobre la figura del censor resultan interesantes las afirmaciones de Itúrbide Díaz, 2007: 72; Caro López, 2003: 197.

${ }^{19}$ AGN, Tribunales Reales. Papeles Varios, Legajo 14, núm. 12, fol. 5 r.

${ }^{20}$ AGN, Tribunales Reales. Papeles Varios, Legajo 14, núm. 12, fol. $6 r$.

${ }^{21}$ AGN, Tribunales Reales. Papeles Varios, Legajo 14, núm. 29, fol. $6 r$. 
de la h delante de algunas vocales se remite al uso constante”, mientras que para Francés "este uso constante no es una regla fija, sino más bien un recurso en defecto de esta" 22 . Sin embargo, pese a su sugerencia dictaminaba que "siendo del superior agrado del Consejo se le pueda conceder la licencia que solicita para la impresión sin necesidad de alterar cosa ninguna" ${ }^{\text {23 }}$.

No obstante, hay ocasiones en que el censor se veía imposibilitado para efectuar su trabajo y lo señalaba de manera explícita. Así sucedió en 1816 cuando Alejandro de Córdoba, a quien se le había encomendado la censura de la traducción al euskera de la obra: Pláticas doctrinales sobre los cinco primeros mandamientos de la ley de Dios. Él mismo expone su "ingenuidad e insuficiencia para el desempeño a causa de que el dialecto euscarano en que está concebida dicha obra es muy distante y diverso del usual y corriente de mi país (en el que tengo una escasa inteligencia) y por consiguiente imperceptible en la mayor parte a mis alcances", lo que provoca que recomiende "confiar este encargo a otro sujeto versado en el idioma y dialecto en que están escritas las referidas pláticas doctrinales" ${ }^{24}$. Una situación que hizo que se remitiese el texto al Provincial de los Trinitarios de la ciudad de Pamplona.

A su vez, son escasísimos los casos en los que el censor, a pesar de que la obra sea ortodoxa, informa negativamente de ella. Bien es cierto que hay veces que se puede apreciar una cierta enemistad o rencor personal hacia el autor de algún libro detrás de los informes que solían redactar los censores. Un claro ejemplo lo tenemos cuando en 1817 fue encargado Antonio María Francés de censurar la Gramática latina escrita por Fray José Carrillo. En su informe señalaba que "la concisión, la brevedad a que el autor procura aspirar es una cualidad recomendable con tal que no se falte a la claridad y exactitud pero aún en esto no ha sido más feliz que en lo primero pues al paso que suprime muchas cosas esenciales el arte de Antonio de Nebrija y substituye otras menos importantes incurre en muchas faltas de exactitud y claridad sin que dejen de encontrarse también varios errores o descuidos ${ }^{25}$. Fruto de la negativa del censor el autor volvió a solicitar un segundo informe censor alegando que "los reparos frívolos, impertinentes y erróneos que ha puesto me persuado firmemente que el censor no ha leído mi arte con aquella imparcialidad y buena fe con que debe proceder el hombre cuando se trata de encontrar la verdad”26. Petición que fue atendida y su obra pasó a la censura de Francisco Zabaleta y José Antonio de Irigoyen, maestros de primeras letras en la Val de Aibar. Ambos tras examinar dicho libro expusieron que la "obra es conforme a la que publicó Antonio Nebrija y que con el nombre de este célebre

\footnotetext{
${ }^{22}$ AGN, Tribunales Reales. Papeles Varios, Legajo 14, núm. 35, fol. 11r.

${ }^{23}$ AGN, Tribunales Reales. Papeles Varios, Legajo 14, núm. 35, fol. 11v.

${ }^{24}$ AGN, Tribunales Reales. Papeles Varios, Legajo 14, núm. 30, fol. 4v.

${ }^{25}$ AGN, Tribunales Reales. Papeles Varios, Legajo 14, núm. 36, fol. 6v.

${ }^{26}$ AGN, Tribunales Reales. Papeles Varios, Legajo 14, núm. 36, fol. 14r.
} 
gramático se usa con aplauso general en las escuelas de latinidad, solo se diferencia en que éste propone las reglas y preceptos en idioma latino y al Padre Carrillo las pone en nuestro castellano". Asimismo, señalan que "las observaciones que hace don Antonio Francés y los reparos que pone para reprobar la obra no son de la mayor consideración", por lo que "se puede dar la licencia que solicita para la impresión”27.

En otras ocasiones directamente la censura es negativa. De este modo, cabe destacar que el doctor Miguel de Elizalde en 1801 al recibir el encargo de remitir la censura de la obra: Devota preparación de nueve días para celebrar la fiesta de la Santa Madre Teresa de Jesús, advierte numerosos aspectos reseñables para impedir su publicación. Primero destacaba que a dicho texto "le faltan el nombre y apellidos del autor, que con los del impresor, lugar y año de la impresión deben expresarse en la portada de cada libro según se manda en la Regla X del índice expurgatorio". Tras esto, señala que "en la advertencia que precede a la novena se hallan algunos defectos e inconexiones que ciertamente no la hacen recomendable", mientras que en la novena "no se puede tolerar" que en la quinta estrofa "se digan estas palabras a Dios: Dadme infierno o dadme cielos, vida dulce, sol sin velos". Tampoco "suenan bien los dos primeros versos de la estrofa $6^{a}$, que son estos: si queréis que me estés holgando, por vuestro amor quiero holgar". Según Elizalde "el verbo holgar en la común acepción significa ociar, entregarse al ocio, y nadie puede pensar que Dios quiere que holguemos en este sentido y mucho menos por vía de hábito"28. En consecuencia, "por todo lo cual juzgo que se debe negar la licencia que se solicita para la impresión”29.

En definitiva, como podemos comprobar el filtro de la censura en la Navarra de principios del siglo XIX fue bastante efectivo, pues no sólo se aplicó sobre aquellas obras que podían albergar contenidos polémicos o peligrosos, sino que además cabe afirmar que muchas veces cuando se examinaron aquellos textos se hizo de forma minuciosa y rigurosa. A su vez, debemos resaltar la calidad de la labor censoria porque detrás de ella no sólo nos encontramos con clérigos o miembros de órdenes religiosas, pues al mismo tiempo aparecen maestros de primeras letras, médicos y un sinfín de profesionales avezados en sus materias.

Esto último hace que pensemos en la eficiencia de la censura dada la heterogeneidad de los censores encontrados en estas fechas, desterrando viejas apreciaciones que suelen tildar a la censura aplicada a los textos impresos de vaga y de escasa valía por estar mayoritariamente en manos de religiosos. No obstante, considero que esta afirmación tan generalizada no se cumple, al menos, para los expedientes que han sido estudiados, pues se detallan informes de censura muy exhaustivos, rompiendo con ese tópico tan extendido de la poca utilidad de la censura.

\footnotetext{
${ }^{27}$ AGN, Tribunales Reales. Papeles Varios, Legajo 14, núm. 36, fol. 18r.

${ }^{28}$ AGN, Tribunales Reales. Papeles Varios, Legajo 14, núm. 3, fol. 21v.

${ }^{29}$ AGN, Tribunales Reales. Papeles Varios, Legajo 14, núm. 3, fol. 22r.
} 
Al margen de este procedimiento, si retomamos las distintas fases administrativas que debía superar todo impreso, era tras la pertinente censura -siempre que no hubiese existido problema alguno- cuando se le concedía la licencia de impresión y se devolvía al impresor el original con la firma del Consejo Real con la expresión: "se imprima y presente para la corrección". De este modo, una vez que el impresor tenía en su poder el visto bueno comenzaba su impresión.

Sería después, tras la impresión de todo el cuerpo de la obra, cuando el texto debía ser nuevamente presentado para que los correctores del Consejo ratificasen que su contenido casaba con el original que se había presentado en un primer momento. Así, por ejemplo, en 1825 era Nicolás de Zuasti quien representando a Juan Pío Jaén decía que "presenta para la corrección con arreglo a lo mandado por vuestro consejo el libro impreso: Ensayo sobre el principios generador o creador de las constituciones políticas y demás instituciones hermanas, y para que pueda circularse a vuestra majestad suplica mande remitirlo a la corrección de la persona que sea del agrado de vuestro consejo" ${ }^{30}$. Se iniciaba entonces una fase centrada en el cotejo del texto impreso.

Era el Consejo Real el encargado de solicitar a expertos correctores, casi siempre religiosos, el cotejo de las obras impresas para comprobar que todas ellas coincidían con el original presentado y que, por tanto, no se habían registrado alteraciones en los textos finales ${ }^{31}$. El revisor examinaba los pliegos impresos con el original autorizado y señalaba los cambios advertidos con indicación de la página y la palabra o término que correspondía sustituir junto a la modificación que debía ser introducida. Todo este proceso culminaba con una declaración en la que se solía confirmar que la obra se ajustaba al original autorizado previamente.

Es lo que conocemos como la fe de erratas, una lista de enmiendas que podemos apreciar gracias a los expedientes conservados en las primeras décadas del XIX. Una época en la que todavía se registraban abundantes errores tipográficos (palabras erróneas por un orden defectuoso de las letras o por ausencia de las mismas, palabras inexistentes y expresiones poco apropiadas dependiendo del texto) a tenor de las referencias que se conservan. De ahí la importancia que este proceso de detección de erratas siguió ostentando.

Por último, una vez que los correctores habían comprobado que todo estaba perfecto era entonces cuando el Consejo Real procedía a fijar el precio al que debía ser vendido el libro en cuestión y cerraba el expediente de autorización de dicho impreso con una expresión muy clara: "circule”; en referencia a que ya podía comercializarse.

\footnotetext{
${ }^{30}$ AGN, Tribunales Reales. Papeles Varios, Legajo 14, núm. 57, fol. 4r.

${ }^{31}$ Sobre la importancia y el valor del cotejo para comprobar que el texto impreso era idéntico al presentado de forma manuscrita puede consultarse: Ezquerra Revilla, 2014: 301; Itúrbide Díaz, 2007: 73; Bragado Lorenzo, 2004: 593.
} 
Figura 3. Fe de erratas: Carta instructiva del soldado católico (1815)

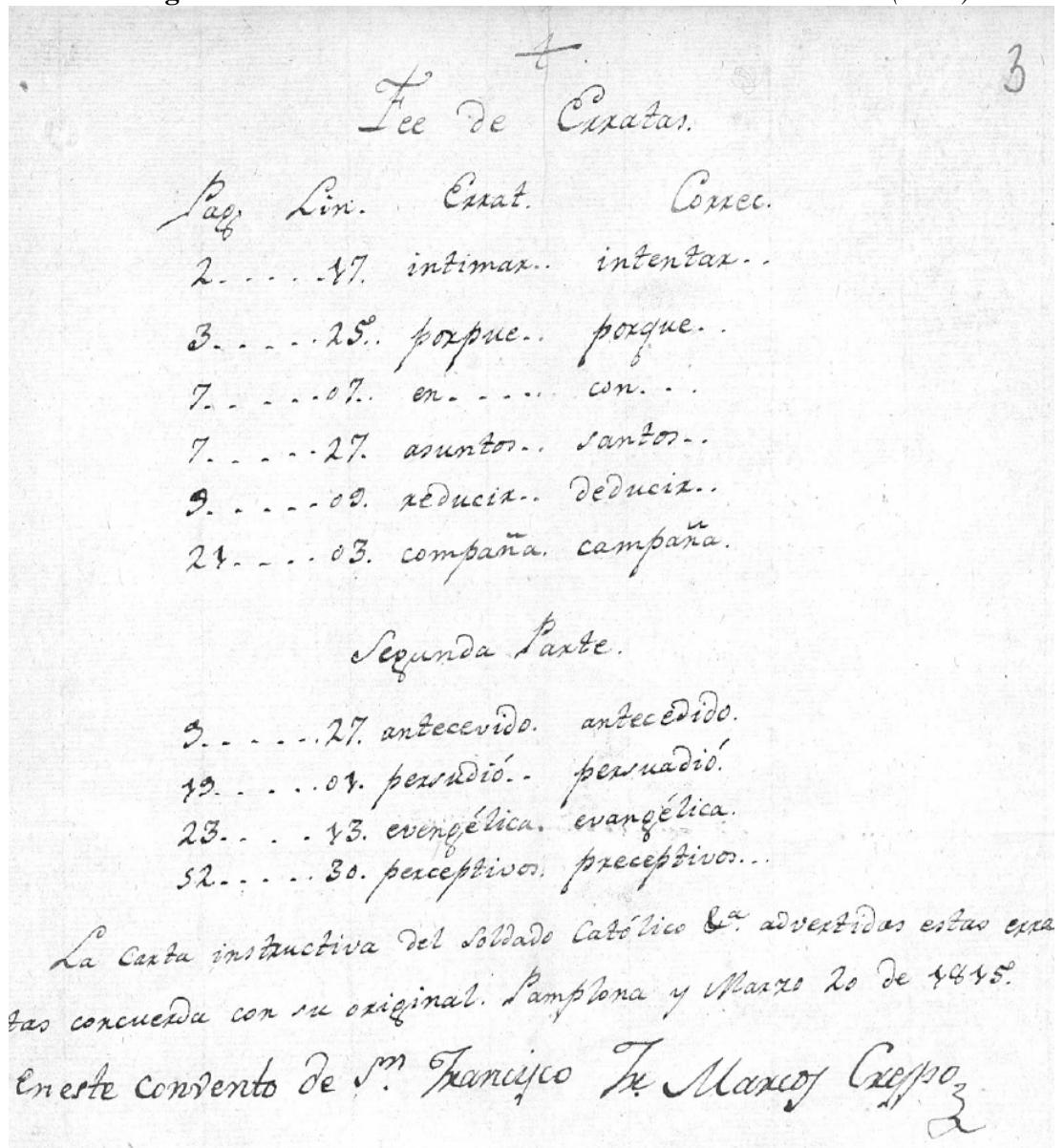

AGN, Tribunales Reales. Papeles varios, legajo. 14, núm. 20, fol. 3r. 
Figura 4. Fe de erratas: Jaungoicoaren aguindubeetaco lehengo bostean icasiquizunac (1816)<smiles>c1ccccc1</smiles><smiles>C=CC(C)(C)C</smiles>
ertifico is el impraescrito Religions de este (onv. de Santiug orden de Predicadores de esta cindad, como habiendo cotejado, por or den del Concyo, el tibro impreso en basquence, intitulado Jaumpoicu aren aprinonbetaco Lelenso basten Ycasignimunac, con sw origi nal; to he hallado en todo conforme ael, emendadas las errar tar igmientes

EnelProlago. Numero VI. linea T. aurreitu, corrigare aurreratue. Piaticas. Fotio 10. lin 18. anditasma, corry anditasma. fol. 40. Lin. 36 . cen, corris ceu. Fot. 67 lin. 28. suzes, corry. swzco. 701. 179. lim. 17 guindu, corry, aguindu. Jol. 188. lin. 3. rjacue, corrij. Jacue Jol. idem lin. 4. Tiagwimizan, corry. Jagniturijan tol. 210. in 3. Erromacuaren, corry. Erromacua.

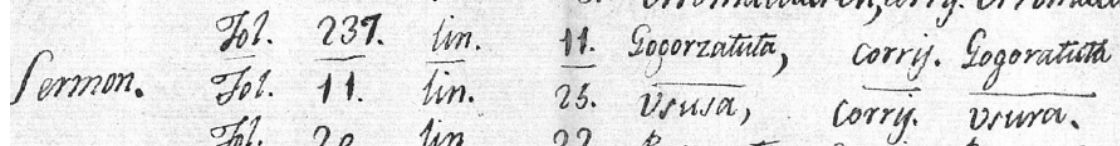
501. 20 lin 22. Parcacuten Corry. Parcatuten.

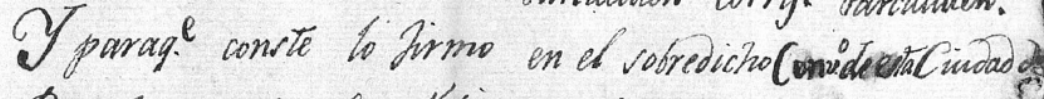
Pampiona a 17. de Nobiembre de 1816. He Peoro Niconte de Berretragar
Lector de Filovojia

AGN, Tribunales Reales. Papeles varios, legajo. 14, núm. 30, fol. 7r. 
En definitiva, todo texto que desease ser impreso y comercializado en el Reino de Navarra a principios del siglo XIX debía superar una serie de trámites administrativos que eran gestionados por el Consejo Real. Sin duda, gracias a los expedientes conservados en el Archivo General de Navarra podemos reconstruir detenidamente los distintos procedimientos. De este modo, hemos profundizado en la labor de los censores, atisbando su celo y rigurosidad como piezas clave para la autorización de aquellos textos, aunque no menos relevante ha sido descubrir el importante papel que desempeñaron los correctores a través de la fe de erratas para que los textos fuesen publicados de manera pulcra. Asimismo, se han detectado las diferentes estrategias que pusieron en marcha los editores a través de las peticiones de licencia que cursaban al Consejo Real. Resumiendo, hemos conseguido bucear en la intrahistoria del entramado editorial existente en la Navarra de finales del Antiguo Régimen.

\section{EL LIBRO EN NAVARRA A PRINCIPIOS DEL SIGLO XIX}

Una vez desmenuzado el procedimiento administrativo a la hora de solicitar una licencia de impresión en el Reino de Navarra es momento de centrarnos en otros aspectos que nos muestran los expedientes que han sido estudiados, que no es otra cosa que las características de la industria editorial local a principios del siglo XIX. De esta manera, entre los aspectos que nos manifiestan estos expedientes tendríamos los siguientes: permiten conocer quiénes fueron los editores, las materias de los libros que se deseaban editar, las lenguas empleadas en aquellas obras, así como la identidad y procedencia de los autores de las mismas. En suma, nos ofrecen multitud de datos que debemos aprovechar para conocer un poco mejor la Historia del Libro en el Reino de Navarra entre 1801 y 1831.

\section{1 ¿QUIÉNES ERAN LOS EDITORES?}

En primer lugar vamos a detenernos en la figura del editor, o mejor dicho editores. Tanto es así que conocer la identidad de estos personajes nos aportará una rica información sobre múltiples aspectos, como por ejemplo el origen y los motivos de la iniciativa editorial. De este modo, desentrañar quien estaba detrás de aquellas ediciones resulta crucial a la hora de reconstruir la historia del libro. En nuestro caso he creído conveniente diferenciar la figura del editor en cinco grupos. Como vemos en la distribución porcentual dos de ellos sobresalen sobre el resto, nos estamos refiriendo tanto a los editores profesionales (impresores y libreros que ostentan el 34\% de las peticiones de licencia estudiadas) como a los autores (representados en el 30\% de los expedientes analizados). Detrás de ambos aparecen los editores capitalistas (20\%), los editores públicos (11\%) y, por último, la escasa representación del poder religioso como editor (5\%). 
Vemos, por tanto, que impresores y libreros acaparan una tercera parte del negocio editorial en el reino, lo que constituye un claro síntoma de la vigorosidad de la iniciativa privada por parte de los profesionales de la industria tipográfica. Bien es cierto que junto a ellos debemos destacar la pujanza de los autores, quienes en numerosas ocasiones actuaron como los editores de sus propios textos, en un afán no sólo de publicar sus obras sino también de tratar de obtener algún rédito económico de ello. Un hecho que les uniría con la figura de los editores capitalistas, quienes tuvieron como única finalidad la obtención de ingresos financieros al promover la edición de textos a los que les auguraban un cierto éxito editorial. Por tanto, no podemos afirmar que el mercado editorial estuviese repartido de un modo equilibrado, pues estos tres grupos ostentaron claramente un papel casi hegemónico. Si bien el hecho de que nos encontremos con editores públicos y religiosos hace que el espectro de materias publicadas, como veremos después, sea sumamente heterogéneo.

Gráfico 2. Porcentajes según el tipo de editor

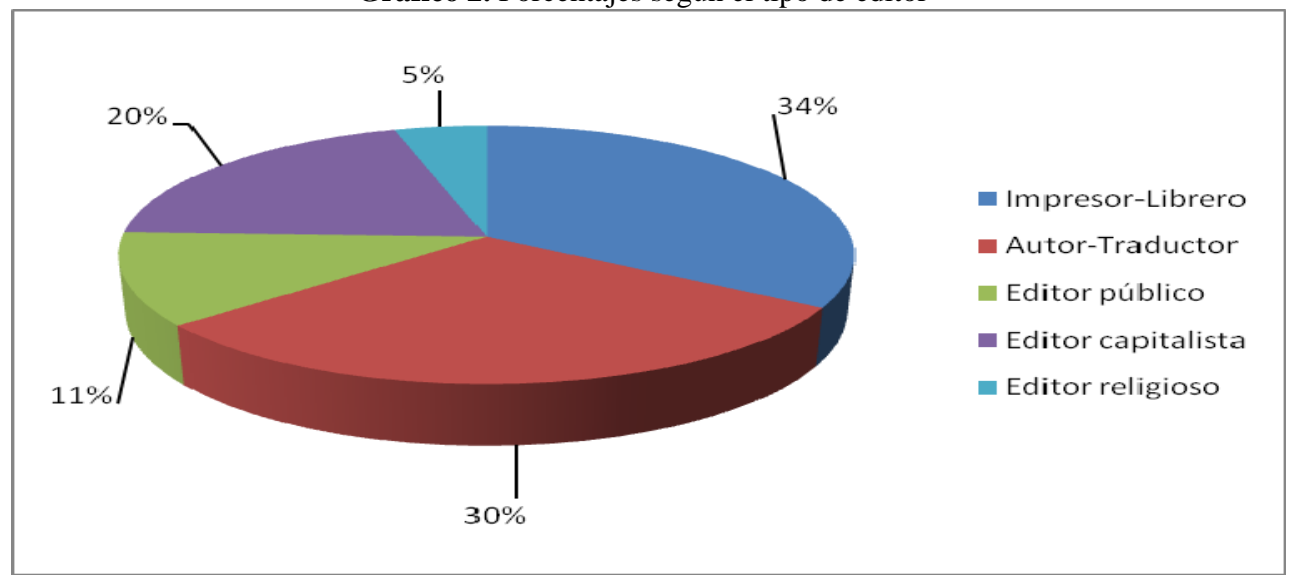

Dicho esto, es momento de profundizar brevemente en cada uno de los grupos expuestos y comprobar sus elementos característicos, así como las personas o instituciones que estuvieron detrás de todos ellos. Primeramente debemos detenernos en el tipo de editor más habitual tras las peticiones de licencia, que no es otro que el editor profesional, detrás del cual nos encontramos tanto a impresores como libreros. En definitiva, se agrupan los promotores de libros que invertían en la impresión y distribución de determinadas obras para obtener un beneficio económico con su posterior venta (López, 2003: 360-361). Como es lógico, esa motivación hizo que este tipo de editores tuviesen unos criterios muy diferentes a la hora de seleccionar los textos a publicar.

Dentro de este apartado de editores profesionales que hacen del mercado del libro un oficio o también una fuente adicional de negocio, debo mencionar, en 
primer lugar, al colectivo de impresores que al mismo tiempo eran propietarios de una librería. Sin duda, se trata de la figura más habitual en los expedientes que han sido analizados, pues debemos pensar que se trataba de las personas que tenían un mayor número de recursos a su alcance: disponían de un taller, de aprendices y oficiales a su cargo, contaban con una librería y, por último, con toda una red de contactos comerciales. Por estos motivos los titulares de un negocio de imprenta y librería fueron los principales agentes del mercado del libro en las primeras décadas del siglo XIX. En nuestro caso debemos destacar cuatro grandes figuras: Joaquín María y José Domingo (Constituciones sinodales del obispado de Pamplona en 1804 o la Carta instructiva al soldado católico de Fray Diego José de Cádiz en $1815^{32}$ ), Javier Gadea (Oración y meditación de Fray Luis de Granada en 1818), Paulino Longás (Catecismo histórico o compendio de la Historia Sagrada y de la Doctrina Cristiana para la instrucción de los niños en 1831) y Francisco Erasun (Exercicio quotidiano con diferentes oraciones y devociones para antes y después de la confesión y sagrada comunión en 1829).

No quiere decir esto que no nos encontremos con impresores que únicamente actuaban como editores, pero que no disponían de un local destinado a la venta de libros. Un claro ejemplo lo tendríamos en la figura de Francisca Andueza, viuda de José Longás, quien en 1803 solicitó la licencia para reimprimir el Libro de la oración y meditación compuesto por Fray Luis de Granada. A su vez, también se podía dar la circunstancia de que un librero actuase como editor. Por lo general, cuando éste advertía que la demanda de una obra era constante o comprobaba que estaba agotada se solía animar a editarla para evitar intermediarios y hacerse con todo el margen comercial. Bien es cierto que esta figura no fue muy frecuente en el caso navarro. Así, por ejemplo, podemos destacar únicamente a Antonio Chueca, maestro librero afincado en Pamplona, quien en 1805 solicitó al Consejo la licencia para publicar el Elogio del General Gravina.

Tras impresores y libreros figuran aquellos particulares que actuaron como autores-editores al desear difundir en un momento determinado un original propio mediante su impresión. Un hecho que pudo deberse a distintas motivaciones. Entre ellas, cabe destacar el hecho de que muchos de ellos no se fiasen de terceras personas que quisiesen aprovecharse de sus textos de forma malintencionada ${ }^{33}$, aunque también puede ser que ante la falta de editores solventes decidiesen optar por financiar y comercializar sus textos. Dentro de éstos debemos mencionar a distintos profesionales que promovieron obras relacionadas con su actividad o desempeño laboral, caso de los médicos.

${ }^{32}$ La obra de Diego José de Cádiz tuvo un destacado protagonismo en la agitación popular antifrancesa de principios del siglo XIX. Consúltese Fernández Sebastián, 1989: 596.

${ }^{33}$ Muchos autores sufrieron las malas prácticas de editores que trataron de aprovecharse de ellos aumentado el número de ejemplares impresos frente a lo acordado en los contratos de edición o empeorando la calidad de las obras para reducir costes. (Bouza, 1997: 35); (Moll, 2011: 284). 
Así Ignacio Paramo, maestro cirujano, deseaba en 1820 dar a conocer las curaciones efectuadas en varios pacientes con úlceras, por lo que "deseando que el público tenga noticia de todo ello para el mayor alivio de los que padecen esa indisposición" pedía que "pueda imprimir los ejemplares que tenga por conveniente" $^{34}$ el Consejo Real. Ya en 1825 cabe destacar a José María Vallearena, médico del Hospital General, quien señalaba que "desea dar a luz la obra que ha compuesto intitulada: Lecciones elementales de anatomía descriptiva”35. Sin embargo, algunas veces estos personajes actuaban como traductores, caso de Vicente Martínez que en 1805 solicitaba la licencia para un libro titulado Disertación de los grados de certidumbre de la medicina, que el mismo había "traducido del francés al castellano" 36 de su autor Cabanis.

Por otro lado, también hubo casos de autores-editores que pueden ser calificados como intrépidos, pues ajenos a un mundo profesional que les permitiese tener una economía desahogada empeñaron tanto su tiempo como sus recursos financieros para llevar a la imprenta sus originales. Entre éstos podemos destacar, por ejemplo, los que tuvieron como principal interés difundir los méritos y la fama de un familiar ilustre, así como los que buscaban la exaltación y glorificación a través de acontecimientos históricos. Conviene destacar aquí la figura del párroco de Ustárroz, Andrés Martín, quien en 1825 decía que había "compuesto una obrita titulada: Historia de la Guerra de la división real de Navarra contra el intruso sistema llamado constitucional y su gobierno revolucionario", la cual "deseo de darlo al público"37.

Mientras que, en tercer lugar, tendríamos a un grupo homogéneo de autores que hicieron las veces de editores, pero que con sus textos no buscaron dar al público avances médicos ni difundir determinados acontecimientos históricos, sino que se trataba de textos piadosos destinados a la instrucción tanto de los eclesiásticos como de los feligreses. Cabe destacar por encima de todos la figura de Fray Bartolomé de Santa Teresa, predicador del convento de Carmelitas Descalzos de la villa de Marquina, ya que entre sus solicitudes de licencias de impresión nos encontramos cuatro obras distintas: Jaungoicoaren aguindubeetaco lehengo bostean icasiquizunac (1816), Euscal Errietaco olgueta bat zubien neurrizco-gatz ozpinduba (1816), Jangoicuaren amar aguindubetaco azqueno bosteen (1817) y Eleisaco zazpi sacramentuben ycasiquizunac (1819). A su vez, otros religiosos locales que conviene tener en cuenta serían Miguel de Elizalde, capellán mayor del convento de Agustinas Recoletas de Pamplona, que en 1814 tenía "deseo de imprimir y dar al público la obra que escribió titulada: Disertaciones a favor de la

\footnotetext{
${ }^{34}$ AGN, Tribunales Reales. Papeles Varios, Legajo 14, núm. 49, fol. 1 r.

${ }^{35}$ AGN, Tribunales Reales. Papeles Varios, Legajo 14, núm. 60, fol. 1r.

${ }^{36}$ AGN, Tribunales Reales. Papeles Varios, Legajo 14, núm. 12, fol. 4r.

${ }^{37}$ AGN, Tribunales Reales. Papeles Varios, Legajo 14, núm. 61, fol. 3r.
} 
suprema autoridad del romano pontífice sobre todos los concilios”38. Así como Martín José Marcotegui, presbítero de Azanza, que en 1828 trataba de publicar una obra bajo el título: Compendio de la historia de la aparición de San Miguel de Excelsis y de su antiquísimo santuario en el monte de Aralar.

Asimismo, junto a los textos piadosos también este tipo de autores se lanzaron a la edición de obras destinadas a la educación. Por ejemplo, tendríamos el caso de Fray José Carrillo, predicador en el convento de San Francisco de la ciudad de Sangüesa y preceptor de latinidad, quien en 1817 presentó un libro de Gramática Latina. Junto a este, merece la pena resaltar también el caso de Tomás Ortiz, quien en 1831 señalaba que "desea dar a luz el folleto que ha compuesto titulado: $L a$ mitología para preguntas y respuestas para la instrucción de la juventud"39.

En definitiva, estos personajes aportan un sinfín de estudios al mercado editorial navarro de la época, desde tratados que muestran la curiosidad profesional y científica de un selecto y reducido grupo de profesionales hasta obras de piedad popular muy demandadas en la época, pasando por textos históricos. Unos textos detrás de los cuales se ha podido apreciar una enorme variedad de profesiones, si bien es cierto que por encima del resto sobresalen los religiosos y ciertos profesionales liberales.

Al margen de los editores profesionales y de los autores-editores tendríamos los particulares ajenos a la imprenta que, pese a estar desligados del mercado editorial en un momento determinado decidían intervenir movidos por el ánimo de lucro. Es por ello que pueden ser denominados como editores capitalistas. Tanto es así que al carecer de infraestructuras lo habitual era que se encomendasen a profesionales del sector. En consecuencia, su participación podríamos catalogarla como esporádica y puntual, reduciéndose a incursiones testimoniales en el tiempo.

Uno de ellos sería José Antonio Senosiain, vecino de Pamplona, pues en 1820 indicaba que "tiene dispuesta y traducida al español del original francés la obra" El alma elevada a Dios por las reflexiones y sentimientos del abate Baudrán, "la que por lo interesante de la materia de que se trata desea dar a la prensa” ${ }^{\text {, }}$. Unos años después sería Juan Pío Jaén quien en 1824 señalaba que "desea dar a luz un libro manuscrito intitulado: Ensayo sobre el principio generador o creador de las constituciones políticas y demás instituciones humanas, escrito por el Conde Maistre en francés, y traducido al castellano por el joven difunto Don José Miguel Saenz de Monjarres”41. Por lo tanto, en ambos casos el editor actuaría como agente capitalista para dar al público un texto compuesto por una tercera persona.

No obstante, no sería ésta la única forma de actuar de los editores capitalistas puesto que incluso se ha testimoniado un caso de suscripción como sistema de

\footnotetext{
${ }^{38}$ AGN, Tribunales Reales. Papeles Varios, Legajo 14, núm. 15, fol. 3r.

${ }^{39}$ AGN, Tribunales Reales. Papeles Varios, Legajo 14, núm. 85, fol. 1r.

${ }^{40}$ AGN, Tribunales Reales. Papeles Varios, Legajo 14, núm. 50, fol. 3r.

${ }^{41}$ AGN, Tribunales Reales. Papeles Varios, Legajo 14, núm. 57, fol. $1 \mathrm{r}$.
} 
ventas. Un modelo éste muy extendido en otras partes del continente y que se rastrea también en Pamplona. Sería en 1830 cuando el doctor en medicina y licenciado en cirugía médica y farmacia, Jaime Zalba, quisiese "publicar un periódico mensual de medicina y cirugía” para darlo a sus suscriptores, por lo que indicaba que "faltando esa circunstancia (en referencia a la licencia) no habría acaso quien se subscribiese" ${ }^{\text {,2 }}$. Por tanto, este tipo de personajes lo que buscaban era la rentabilidad de sus aventuras editoriales.

Por otro lado, en cuarto lugar, podemos afirmar que la presencia de editores institucionales en la Navarra del XIX es menos relevante de lo que fue en épocas pasadas, caso de los siglos XVI y XVII, e incluso del XVIII. Bien es cierto que dentro de ellas la que se encarga principalmente de promover la edición de textos fue la Diputación del reino, seguida del Consejo Real, el Regimiento pamplonés o el Hospital General de Pamplona. No debemos olvidar que esta última aún seguía conservando en pleno siglo XIX el monopolio en exclusiva de venta de algunas de las publicaciones con mayor demanda, caso del Arte de Nebrija, el Libro Cuarto de Bravo, la Cartilla, la Doctrina Cristiana o la Gallofa ${ }^{43}$.

Ciertamente cuando hablamos de ediciones institucionales tenemos que tener muy presente la intencionalidad que guiaba aquellas publicaciones. Debemos destacar, por parte de la Diputación del reino, la solicitud de reimpresión y corrección del Fuero General en 1816, así como las peticiones para imprimir el Cuaderno de las leyes de las Cortes de 1819 y 1829. Como vemos, son todas obras de carácter legislativo, y más en el contexto político en el que nos encontramos. Por el contrario, no se ha testimoniado la presencia del Consejo Real en ninguno de los 86 expedientes en los que se solicita la licencia de impresión. Sin embargo, sí nos encontramos con el Regimiento de Pamplona como editor, pues no sólo se encargaba de publicar ordenanzas o bandos, sino que en 1802 presentó un Manifiesto sobre el estado de la casa de misericordia para salvaguarda del Hospital General por su pésimo estado. Junto a él, otra institución de carácter público que se testimonia como editora es el propio Hospital General de la Misericordia, así en 1805 solicitó permiso al Consejo Real para dar "al público el descubierto del presbítero don Juan Manuel de Azpilcueta, relativo a que los paños y lienzos sean impenetrables por el agua"44.

Tras el poder civil, menor relevancia ostentaron las peticiones de licencias de impresión por parte del obispado o las órdenes religiosas. Es lo que debemos denominar como editores religiosos. Sin duda alguna, la producción editorial de las instituciones eclesiásticas está por debajo en número de las civiles, lo que

\footnotetext{
${ }^{42}$ AGN, Tribunales Reales. Papeles Varios, Legajo 14, núm. 80, fol. 1r.

${ }^{43}$ Hecho que generó desde el siglo XVII constantes litigios en los tribunales navarros por la publicación y venta de estas obras sin permiso del Hospital General de Pamplona. Véase Ruiz Astiz, 2015: 332.

${ }^{44}$ AGN, Tribunales Reales. Papeles Varios, Legajo 14, núm. 13, fol. 1r.
} 
también tiene su representación en un menor número de expedientes iniciados por ellas. Tanto es así que ni siquiera encontramos peticiones cursadas por el Obispado o la Diócesis pamplonesa, tan habitual en la edición de textos de carácter normativo, institucional o piadoso.

Sin embargo, lo que sí constatamos es el protagonismo que detentaron algunas órdenes religiosos durante estos años, pues promovieron una cierta actividad editorial para consumo interno, preferentemente. De esta manera, cabe destacar a los Carmelitas Descalzos, quienes presentaron dos solicitudes: la primera para la impresión de la obra Devota preparación de nueve días para celebrar la fiesta de la Santa Madre Teresa de Jesús en 1801 y, después, en 1826 para la publicación de las Constituciones de los carmelitas descalzos. Junto a ellos, podríamos advertir también la licencia que solicitó al Consejo Real la Orden de San Francisco de Asís en 1803 para editar la Cartilla o Reglas para el Convento de San Francisco de Asís.

Resulta evidente que tanto los editores profesionales como los autores cuando ejercieron como editores de sus propios textos fueron los más activos en la demanda de peticiones de licencia a principios del siglo XIX en Navarra, pese a que tampoco podemos menospreciar la relativa pujanza de los editores capitalistas. Cosa distinta será el escaso protagonismo ostentando por las instituciones civiles y religiosas del reino, lo que marca una clara ruptura con el peso que durante los siglos XVI y XVII tuvieron las publicaciones institucionales y eclesiásticas ${ }^{45}$. Ahora, sin embargo, comprobamos una mayor relevancia del libre mercado con la promoción de textos de mano no ya de sus autores o de los profesionales del libro, sino también cada vez más de inversores ajenos al mundo editorial pero guiados por la posibilidad de obtener ingresos económicos cuantiosos dependiendo del producto en el que invirtiesen. Lógicamente las cosas habían ido cambiando paulatinamente en el siglo XVIII, aunque dichos cambios se manifestaron de manera más evidente entre $1801 \mathrm{y}$ 1831. Ligados a la naciente economía de mercado, según Martínez Martín ${ }^{46}$, estas décadas supusieron el punto final de las estrategias comerciales del Antiguo Régimen y la aparición de nuevas reglas del juego.

\subsection{MATERIAS IMPRESAS}

Vista la figura del editor, otro de los aspectos que nos permite conocer cada expediente es la materia de los textos que se querían publicar. Gracias a ello, y tras analizar las 86 peticiones de licencias de impresión podemos establecer, a mi entender, un total de 8 temáticas, aunque la mayor parte de dichas peticiones son para obras religiosas (38\%). No obstante, aparecen otras 7 temáticas que pueden ser desglosadas de la siguiente manera: política-filosofía (14\%), medicina (13\%),

\footnotetext{
${ }^{45}$ Aspecto reseñado en los estudios de Ostolaza Elizondo, 2004: 73; Ruiz Astiz, 2015: 339.

${ }^{46}$ Martínez Martín, 2003: 603-604.
} 
gramática-educación (12\%), historia (10\%), jurisprudencia (8\%), agricultura-caza (4\%) y geografía (1\%).

Gráfico 3. Porcentajes según materias impresas

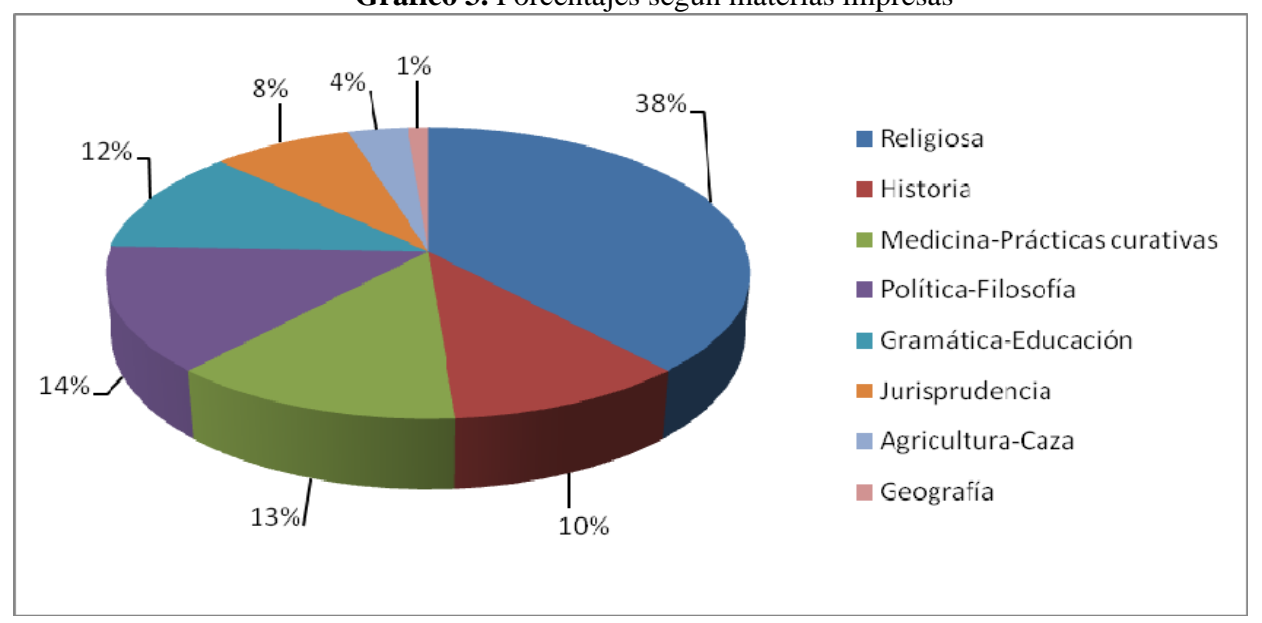

Sin duda alguna, de esta clasificación por materias sobresalen los títulos de naturaleza religiosa, si bien hay una clara preocupación en la época por textos no ya relacionados con la Historia o el Derecho, sino que vemos una especial preocupación por obras de corte político o filosófico y también por las centradas en la medicina y las prácticas curativas. En definitiva, esta diversificación pone de manifiesto no sólo los intereses de los autores y editores locales, ya que al mismo tiempo nos da pautas para conocer o al menos intuir los gustos de los lectores de principios del siglo XIX en el Reino de Navarra. A su vez, nos ayuda a intuir la evolución de las materias más demandadas, pero principalmente vislumbra la renovación de los saberes que advierte Buigues (2003: 324) en el panorama hispano entre el siglo XVIII y XIX.

\subsection{LENGUAS EMPLEADAS}

A su vez, junto a la materia de los textos que se deseaban publicar, otro de los aspectos que reflejan las peticiones de licencias de impresión son los idiomas empleados en dichas publicaciones. De este modo, de los expedientes estudiados se desprende el predominio del castellano, ya que el $92 \%$ de las veces es la lengua usada (79 expedientes), aunque no debemos menospreciar el 7\% de los casos (6 expedientes) en los que las obras van a ser editadas en euskera. Y, por último, tendríamos el caso de una obra que se iba a imprimir en bilingüe (1\%), como era la 
Guía de colmeneros o tratado práctico de abejas, la cual sus autores "desean imprimir en los dos idiomas castellano y bascongado" ${ }^{\text {"47 }}$.

Este hecho nos permite conocer, además de la lengua en la que se editaban los textos, otros aspectos, ya que por ejemplo, en las seis ocasiones en las que se cursaron peticiones de licencia para textos en euskera nos encontramos con obras destinadas a la piedad popular, por lo que podría pensarse que el florecimiento en el reino de este tipo de ediciones iba dirigida principalmente a fomentar la vida espiritual del pueblo euskaldún y, a su vez, a revitalizar la lengua.

Como es lógico, después de un período de prohibición de impresión de textos en euskera se produjo un cierto auge de tales publicaciones ${ }^{48}$. Si bien se pone de manifiesto que la lengua más empleada por aquella sociedad, o al menos, en la que más se leía era el castellano. Algo que también podemos llegar a entender porque buena parte de las obras impresas en Pamplona a principios del siglo XIX tenían como destino final el mercado hispano.

Por último, debemos advertir que de las 79 peticiones que se presentan para imprimir textos en castellano, hay 10 casos donde constatamos distintas traducciones efectuadas del francés al castellano. Sin duda, estaríamos ante obras de gran interés o demanda en aquel contexto, como por ejemplo Catecismo histórico o compendio de la Historia Sagrada y de la Doctrina Cristiana, compuesta originariamente en francés por Fleury, o El alma elevada a Dios por las reflexiones y sentimientos que José Antonio Senosiain había traducido al castellano tomando como referencia la obra de Baudrand. Incluso se aprecia que de las 6 peticiones de impresión de textos en euskera hay dos que son traducciones de una obra que originariamente está en castellano, caso de la Doctrina Cristiana de Astete que la tradujeron dos religiosos: Pedro de Añibarro en 1803 y Juan Nicolás de Echeverría en 1825.

De esta manera, constatamos que el $14 \%$ de los expedientes analizados para este artículo hacen referencia a obras traducidas (francés-castellano y castellanoeuskera), cuyo único fin no era otro que lograr una mejor comprensión de los lectores navarros de las primeras décadas del siglo XIX. Un hecho que se constata no sólo por la elección de obras de suma relevancia en aquella época y de otras que todavía seguían estando vigentes, sino porque además están representadas en dichas traducciones las dos lenguas del reino.

\subsection{AUTORES DE LAS OBRAS}

Otro aspecto más que nos permite conocer cada uno de los expedientes que se han analizado son los autores de las obras y su procedencia. Así, por ejemplo,

\footnotetext{
${ }^{47}$ AGN, Tribunales Reales. Papeles Varios, Legajo 14, núm. 71, fol. 1r.

${ }^{48}$ En el caso navarro hubo prohibición de publicar textos en euskera desde 1766 fruto de la política desarrollada por el Conde de Aranda. (Sesé Alegre, 1994: 454); (García Martín, 2003: 233).
} 
podemos destacar autores de renombre como Fray Luis de Granada, Gaspar de Astete, Antonio de Nebrija o el francés Claude Fleury, y otros menos conocidos pero que también deben tener cabida, caso de Fray Bartolomé de Santa Teresa. Este último principalmente porque era coetáneo y por lo que podemos comprobar tuvo una activa presencia entre 1816 y 1819 con cuatro solicitudes distintas para obtener la licencia de impresión para otros tantos libros.

Dicho esto, en cuanto a su procedencia se constata una mayoría aplastante de autores hispanos (51 referencias) frente a los franceses (10 referencias), además cabe destacar la ausencia de autores italianos y latinos. No obstante, resulta llamativo que de 86 peticiones de licencia únicamente conozcamos la autoría de 61 textos, ya que los 25 restantes no se dice nada en los expedientes de autorización de impresiones que se han conservado.

Sin embargo, consideramos oportuno advertir que pese a ese dominio de los autores considerados hispanos no existen un reparto peninsular similar, ya que los navarros son mayoría con 31 referencias $^{49}$, seguidos de los castellanos (10 referencias), vizcaínos (4) y catalanes (2), así como de los alaveses, aragoneses, guipuzcoanos y valencianos que aparecen todos ellos una única vez. Bien es cierto que tampoco debe sorprendernos este hecho porque como es lógico los navarros serían los usuarios más interesados a la hora de tramitar los expedientes de autorización de impresiones ante el Consejo Real, pues el hecho de residir en el reino hacía que tuviesen que solicitar la licencia en Navarra para poder publicar y comercializar sus obras.

Ahora bien, llama la atención la presencia de autores peninsulares que solicitan licencia al Consejo Real para la edición de sus textos. Este no es un hecho novedoso porque tenemos ejemplos muy evidentes en siglos anteriores, pero ahora quizá cobra una mayor relevancia porque con la Real Cédula de 1783 se establece la posibilidad de que un texto impreso en Navarra pueda ser comercializado en el resto de la Península ${ }^{50}$. Por tanto, podemos estar ante autores que habiendo presentado su texto ante el Consejo de Castilla hubiesen recibido una negativa y decidiesen presentarlo en Navarra para tener una segunda oportunidad. Puede ser también que directamente lo presentasen en nuestro reino por su cercanía, caso de los autores vascos, o bien porque considerasen que podía ser más sencillo imprimirlo en Pamplona y escapar así de la férrea censura ejercida en Castilla.

A su vez, los autores franceses aparecen en 10 ocasiones entre los expedientes conservados, fundamentalmente por las traducciones que se llevan a cabo al castellano de las obras de moda del momento. Fruto de esta situación es lógico que aparezcan libros de Fleury (Catéchisme historique, contenant en abrégé l'histoire

49 Entre ellos podríamos destacar a Manuel de Ormaechea, Tadeo Echávarri, José María de Zuaznavar, José María de Vallearena, Tomás Ortiz o Martín José Marcotegui.

${ }^{50}$ Para profundizar más sobre este aspecto merece la pena consultar las aportaciones de Reyes Gómez, 2000: 616; García Cuadrado, 1996: 166 y García Martín, 2003: 258. 
sainte et la doctrine chrétienne), Pey (Traité de l'autorité des deux puissances), Baudrand (L'âme élevée à Dieu) y Maistre (Essai sur le principe générateur des constitutions politiques et des autres institutions humaines), entre otros.

En suma, los autores de las obras para las que se piden licencia son escritores modernos, generalmente coetáneos al período estudiado o fallecidos en la segunda mitad del siglo XVIII. Lo que se constata es que detrás de las peticiones de licencia conservadas no hay ya un predominio de autores clásicos, como podía suceder en el siglo XVI, y ni mucho menos aparecen con la hegemonía que caracterizó al XVII personajes como Antonio de Nebrija, Gaspar de Astete o Fray Luis de Granada. Hay un cambio evidente que trajo consigo, como hemos visto, un mayor interés por obras contemporáneas relacionadas con géneros más atractivos y demandados en aquella coyuntura histórica, caso de textos filosóficos o sobre avances médicos, sin menospreciar ni mucho menos los de carácter religioso.

De este modo, el autor que encontramos detrás de las peticiones de licencia de principios del siglo XIX sería, a grandes rasgos, nacido a finales de la centuria anterior, mayoritariamente de origen navarro y de profesiones muy variadas (religioso, jurista, médico, maestro, etc.). Toda esta heterogeneidad lo que manifiesta es la efervescencia del momento y los nuevos gustos de la sociedad navarra de finales del Antiguo Régimen.

\section{CONCLUSIONES}

Resaltaba Moll (2011: 11) en su célebre estudio sobre los Problemas bibliográficos del libro en el Siglo de Oro que para conocer en profundidad los avatares de la edición de textos en la Monarquía Hispánica debíamos ser conscientes de las peculiaridades administrativas de cada territorio. Su acertada observación ha hecho que en los últimos años el estudio del libro se haya abordado desde un prisma más certero, pues ya no se entienden los impresos como objetos bibliográficos ajenos a un contexto político y legal, sino que se estudian en una dimensión más completa. Es aquí donde tenemos que ser conscientes de la excepcionalidad que representó el Reino de Navarra todavía hasta 1841, momento en que pasó a ser una provincia más y perdió su entramado institucional y legal.

El presente artículo ha conseguido sentar las bases del funcionamiento del Consejo Real en materia de imprenta durante las convulsas primeras décadas del siglo XIX. Salta a la vista que en nuestra tierra no asistimos al frenesí administrativo que experimentó durante las mismas fechas el Consejo de Castilla, pero gracias al estudio de los expedientes de autorización de impresiones conservados en el Archivo General de Navarra podemos aproximarnos de forma certera al mercado editorial navarro de la época.

Sin duda, y pese a lo que pueda pensarse, ha quedado demostrado que aun tratándose de un territorio con escasa relevancia en el circuito librario europeo, asistimos al exquisito celo con el que el Consejo Real de Navarra atendía sus 
cometidos en relación con la imprenta. Por tanto, como hemos constatado, las autoridades del reino se esmeraron en la medida de lo posible por controlar y gestionar todo aquello que estuviese relacionado con la producción y comercialización de libros.

Asimismo, el análisis de los expedientes nos ha permitido trazar fielmente los procedimientos administrativos que todo texto debía superar para ser publicado en el reino. Un hecho que ha favorecido que tengamos un mejor conocimiento del libro impreso en la Navarra de principios del XIX, pues se han desentrañado distintos aspectos del negocio editorial, caso de la figura del editor, las materias o temáticas más usuales, los idiomas empleados o los autores más prolíficos de aquella coyuntura histórica.

Este estudio supone, en definitiva, un avance en la historia de la imprenta en Navarra que viene a sumarse a los que se han ido elaborando hasta la fecha, los cuales se han centrado principalmente en los siglos XVI, XVII y XVIII. Debido a ello, el valor del presente artículo es mayor si cabe porque no existían investigaciones que analizasen la Historia del Libro en el reino entre 1801 y 1831. A lo que debemos sumar el hecho de haber sido analizada una fuente extraordinaria por la información que ofrece sobre el procedimiento administrativo en todo lo relacionado con la edición de libros. Un hecho, este último, que debe ser resaltado porque nos encontramos ante los únicos testimonios documentales que se conservan para el caso navarro.

\section{REFERENCIAS BIBLIOGRÁFICAS}

ÁLVAREZ CORA, Enrique (2003). "Expedientes de censura y licencia de libros jurídicos en los últimos años del siglo XVIII y primeros del XIX”. Anuario de Historia del Derecho Español, $\mathrm{n}^{\circ} 73$, pp. 289-314.

BENITO ORTEGA, Vanesa (2011). "El Consejo de Castilla y el control de las impresiones en el siglo XVIII. La documentación del Archivo Histórico Nacional”. Cuadernos de Historia Moderna, n 36, pp. 179-193.

BOUZA, Fernando (1997). "Para qué imprimir. De autores, público, impresores y manuscritos en el Siglo de Oro”. Cuadernos de Historia Moderna, $\mathrm{n}^{\circ} 18$, pp. 31-50.

BRAGADO LORENZO, Javier; CARO LÓPEZ, Ceferino (2004). "La censura gubernativa en el siglo XVIII”. Hispania, no 217, vol. 64-2, pp. 571-600.

BUIGUES, Jean-Marc (2003). "Las materias: tradición y modernización”, en Historia de la edición y de la lectura en España: 1472-1914. Madrid: Fundación Germán Sánchez Ruipérez, pp. 317-327.

CARO LÓPEZ, Ceferino (2003). "Los libros que nunca fueron. El control del Consejo de Castilla sobre la imprenta en el siglo XVIII”. Hispania, n ${ }^{\circ} 213$, vol. 63-1, pp. 161-198. 
CCPB: Catálogo Colectivo del Patrimonio Bibliográfico Español (2015). $<$ http://ccpb_opac.mcu.es/CCPBopac>. [Consulta: 30/07/2015].

DOMERGUE, Lucienne (1977). “Apuntes sobre la legislación de imprentas: Fuero de Navarra y centralismo castellano a fines del Antiguo Régimen”. Boletín de la Real Academia de la Historia, CLXXIV, pp. 197-215.

EZQUERRA REVILLA, Ignacio (2014). "El Consejo Real de Castilla y la autorización administrativa de impresión de libros en el siglo XVI”. Obradoiro de Historia Moderna, $\mathrm{n}^{\circ}$ 23, pp. 295-324.

FERNÁNDEZ SEBASTIÁN, Javier (1989). “Opinión pública, prensa e ideas políticas en los orígenes de la Navarra contemporánea, 1762-1823”. Príncipe de Viana, vol. 50, no 188 , pp. 579-640.

FSS: Fundación Sancho el Sabio (2015). <http://catalogo.fsancho-sabio.es/>. [Consulta: 31/07/2015].

GARCÍA CUADRADO, Amparo (1996). “Aproximación a los criterios legales en materia de imprenta durante la Edad Moderna en España”. Revista General de Información y Documentación, $\mathrm{n}^{0}$ 6-2, pp. 125-187.

GARCÍA MARTÍN, Javier (2003). El juzgado de imprentas y la utilidad pública. Cuerpo y alma de una Monarquía vicarial. Bilbao, UPV-EHU.

GARCÍA PÉREZ, María Sandra (1998). "Imprenta y censura en España desde el reinado de los Reyes Católicos a las Cortes de Cádiz: un acercamiento a la legislación”. Boletín de la ANABAD, no 48-2, pp. 197-204.

GARCÍA PÉREZ, Rafael (2002). "El Consejo Real de Navarra, entre el derecho del rey y las libertades del reino (1800-1836)". Anuario de Historia del Derecho Español, no 72, pp. 125-200.

GIL NOVALES, Alberto (2012). "La libertad de imprenta entre dos revoluciones: de Cádiz al Trienio", en El nacimiento de la libertad de imprenta. Antecedentes, promulgación y consecuencias del Decreto de 10 de noviembre de 1810. Madrid: Sílex, pp. 391-413.

ITÚRBIDE DÍAZ, Javier (2007). Escribir e imprimir. El libro en el Reino de Navarra en el siglo XVIII. Pamplona, Gobierno de Navarra.

LÓPEZ, François (2003). "Los editores", en Historia de la edición y de la lectura en España: 1472-1914. Madrid: Fundación Germán Sánchez Ruipérez, pp. 358-367.

LÓPEZ PIÑEIRO, José María (1991). Bibliographia medica hispanica, 14751950. Volumen IV: Libros y Folletos, 1801-1850. Valencia, Instituto de Estudios Documentales e Históricos sobre la Ciencia.

MARCUELLO BENEDICTO, Juan Ignacio (1999). "La libertad de imprenta y su marco legal en la España liberal”. Ayer, n ${ }^{\circ} 34$, pp. 65-92.

MARTÍNEZ MARTÍN, Jesús (2003). "Editores y empresas editoriales", en Historia de la edición y de la lectura en España: 1472-1914. Madrid: Fundación Germán Sánchez Ruipérez, pp. 601-608. 
MIRANDA RUBIO, Francisco (2014). La encrucijada liberal: el final de la ocupación napoleónica en Navarra. Pamplona, Gobierno de Navarra.

MOLL, Jaime (2011). Problemas bibliográficos del libro del Siglo de Oro. Madrid, Arco Libros.

NAVARRO MARCHANTE, Vicente (2011). "El Decreto IX de las Cortes de Cádiz de 1810 sobre la libertad de imprenta”, en El legado de las Cortes de Cádiz. Valencia: Tirant lo Blanch, pp. 335-354.

OSTOLAZA ELIZONDO, María Isabel (2004). Impresores y libreros en Navarra durante los siglos $X V$-XVI. Pamplona, Universidad Pública de Navarra.

PALAU Y DULCET, Antonio (1953). Manual del librero hispano-americano: bibliografía general española e hispano-americana desde la invención de la imprenta a nuestros tiempos. Barcelona, Palau, vol. 6: G-H.

PÉREZ GOYENA, Antonio (1953-1961). Ensayo de bibliografía navarra: desde la creación de la imprenta en Pamplona hasta el año 1910. Pamplona, Príncipe de Viana, vols. 6-7.

PÉREZ JUAN, José (2006). "La aplicación de la ley de imprenta de 15 de marzo de 1837”. Anuario de Historia del Derecho Español, n 76, pp. 667-704.

REYES GÓMEZ, Fermín (2000). El libro en España y América. Legislación y censura (siglos XV-XVIII). Madrid, Arco Libros.

RUIZ ASTIZ, Javier (2015). "Litigantes ante los Tribunales Reales de Navarra: impresores y libreros durante los siglos XVI y XVII". Titivillus. Revista internacional sobre libro antiguo, $\mathrm{n}^{\circ} 1$, pp. 325-340.

SALCEDO IZU, Joaquín (1982). "La imprenta en la legislación histórica de Navarra”, en Historia de la imprenta hispana. Madrid: Editora Nacional, pp. 645-677.

SESÉ ALEGRE, José María (1994). El Consejo Real de Navarra en el siglo XVIII. Pamplona, Eunsa. 